Fossh Energy Program

Fossll Energy Program

Fossil Energy Program

Fossli Energy program

Fossil Evergy program

Fossil Energy Program

Fossl Energy Program

Fossil Energy Program Fossil Energy Program Fossil Energy Program Fossil Energy Program Fossil Energy Program Fossil Energy Program

Fossul Energy Program

Fossli Eneryy program

Fossil Energy Program

possll Energy Program

Fossil Energy Program

Fossil Energy Program

Fossil Energy program

Fossil Energy Program

Fossll Energy Progran

Fossil Energy program

Fossil Eneroy program

Fossll Energy Progrem

Fossul Energy Program

Fossll Energy Program

Fossil Energy program

Fossll Energy program

Fossil Energy program

Fossil Energy Program

Fossil Energy Program

Fossul Energy Program

\title{
Spallation Studies on Alumina-Forming Model Alloys
}

\author{
by T. Rieck, S. Majumdar, \\ and K. Natesan
}

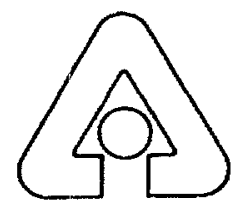

Argonne National Laboratory, Argonne, Illinois 60439

operated by The University of Chicago

for the United States Department of Energy under Contract W-31-109-Eng-38

\section{Energy Technology \\ Diviston \\ Energy Technology \\ Division \\ Energy Technology \\ Division}

Energy Technology

Diviston 
Argonne National Laboratory, with facilities in the states of Illinois and Idaho, is owned by the United States Government and operated by The University of Chicago under the provisions of a contract with the Department of Energy.

\section{DISCLAIMER}

This report was prepared as an account of work sponsored by an agency of the United States Government. Neither the United States Government nor any agency thereof, nor The University of Chicago, nor any of their employees or officers, makes any warranty, express or implied, or assumes any legal liability or responsibility for the accuracy, completeness, or usefulness of any information, apparatus, product, or process disclosed, or represents that its use would not infringe privately owned rights. Reference herein to any specific commercial product, process, or service by trade name, trademark, manufacturer, or otherwise, does not necessarily constitute or imply its endorsement, recommendation, or favoring by the United States Government or any agency thereof. The views and opinions of document authors expressed herein do not necessarily state or reflect those of the United States Government or any agency thereof, Argonne National Laboratory, or The University of Chicago.

Available electronically at http://www.doe.gov/bridge

Available for a processing fee to U.S. Department of Energy and its contractors, in paper, from:

U.S. Department of Energy

Office of Scientific and Technical Information

P.O. Box 62

Oak Ridge, TN 37831-0062

phone: (865) 576-8401

fax: (865) 576-5728

email: reports@adonis.osti.gov 


\section{DISCLAIMER}

Portions of this document may be illegible in electronic image products. Images are produced from the best available original document. 
ARGONNE NATIONAL LABORATORY

9700 South Cass Avenue

Argonne, IL 60439

\title{
RECEIVED \\ NOV 152000 \\ OSTI
}

ANL/FE-00-01

\section{SPALLATION STUDIES ON ALUMINA-FORMING MODEL ALLOYS*}

\author{
by \\ T. Rieck, S. Majumdar, and K. Natesan \\ Energy Technology Division
}

April 2000

Work funded by

DOE/Fossil Energy, Advanced Research and

Technologies Development and

DOE/Office of Science, Basic Energy Sciences. 



\section{CONTENTS}

Abstract.

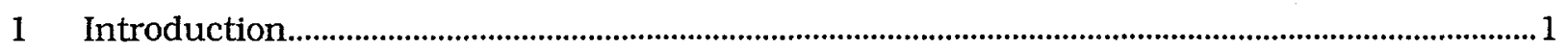

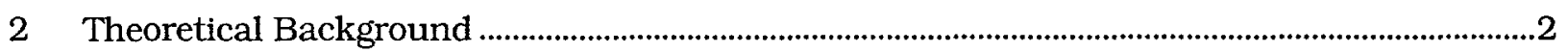

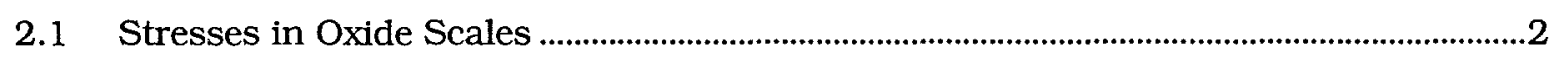

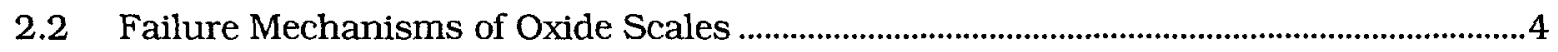

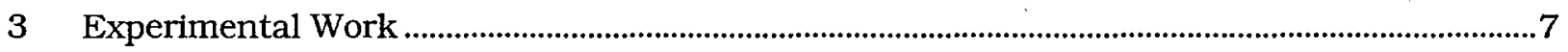

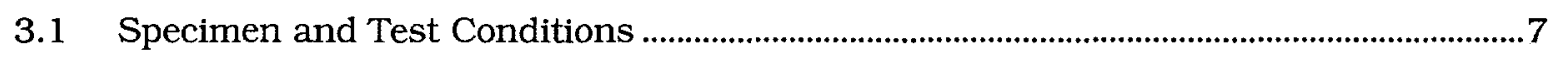

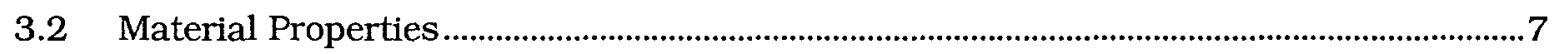

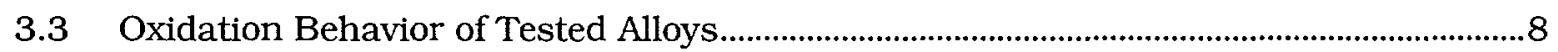

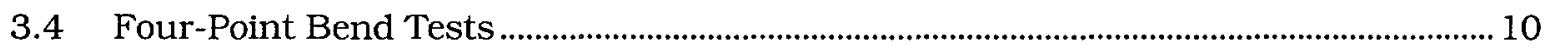

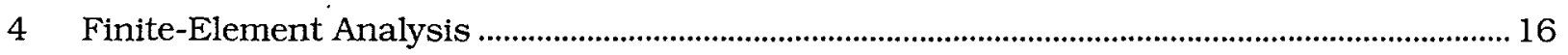

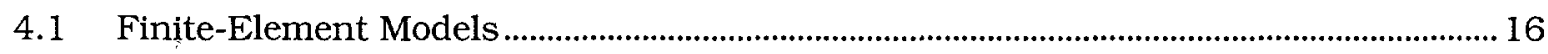

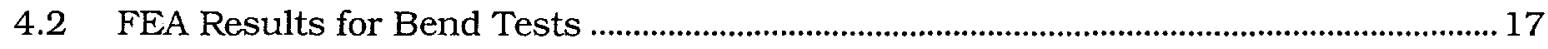

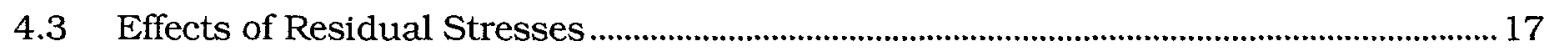

4.4 Fracture Mechanics Modeling of Spallation .....................................................................20

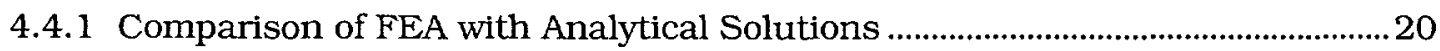

4.4.2 FEA Solutions for Metal/Oxide Systems......................................................................2 22

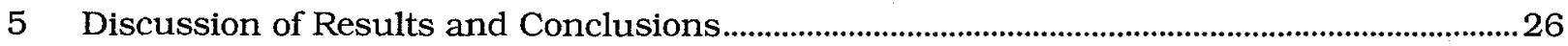

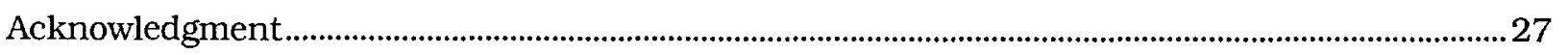

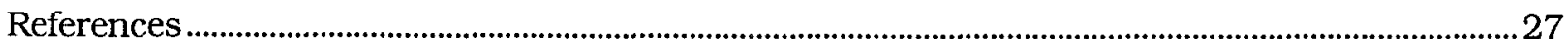




\section{FIGURES}

1. Alloy and oxide in stress-free initial condition.

2. Oxide spallation for mode I wedging process and mode II buckling process. 4

3. Plane strain geometry of crack tip.

4. Critical strains to scale failure under tensile stresses for various oxides as a function of defect size.

5. Cyclic oxidation behavior of Ni-based model alloys after 500 -h exposure at $1000^{\circ} \mathrm{C}$ in air. 9

6. Cyclic oxidation behavior of Ni-based model alloys 1 and 2 at $1200^{\circ} \mathrm{C}$ in air.

7. Surfaces of specimens oxidized in air for $200 \mathrm{~h}$ at 1000 and $1200^{\circ} \mathrm{C}, 500 \mathrm{~h}$ at $1000^{\circ} \mathrm{C}$, and $500 \mathrm{~h}$ at $1200^{\circ} \mathrm{C}$.

8. Geometry and loading configuration of four-point bend tests.

9. Surface of Alloy 1 after bend test at room temperature under stress condition of 829.05 MPa.

10. Surface of Alloy 2 with $1.5-\mu$ m-thick oxide scale after bend test at room temperature under stress condition of $763.51 \mathrm{MPa}$

11. Surface of Alloy 2 after bend test at room temperature under stress condition of $503.43 \mathrm{MPa}$.

12. Mesh and boundary conditions used in finite-element calculation to calculate stresses in oxidized samples.

13. Mesh and boundary condition of sample with interface crack

14. Normalized bending stress in oxide scale with different thicknesses of Alloys 1 and 2.

15. Normalized bending stress in oxide scale with different thicknesses of Alloy 3.

16. Effect of residual stress on bending stress in tensile side of Alloys 1 and 2 during bend test with force of $300 \mathrm{~N}$.

17. Interfacial crack in bimaterial four-point bend specimen. 20

18. Comparison of normalized strain energy release rate calculated analytically and by FEM for several Young's modulus ratios. 
19. Normalized strain energy release rates calculated analytically and by FEA using steady-state values for two crack lengths, and virtual crack extension method with $\Delta \mathrm{a}=0.05 \mathrm{~mm}$

20. Comparison of strain energy release rates of Alloys 1 and 2 at room temperature and $1000^{\circ} \mathrm{C}$, and Alloy 3 at room temperature for different scale thicknesses.

21. Strain energy release rate of oxide/alloy interface crack at one end of sample after cooling from high temperatures. 


\section{TABLES}

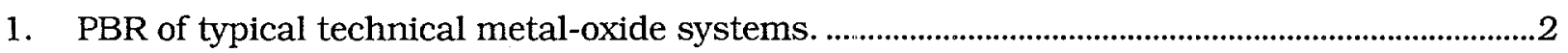

2. Growth and residual stresses in alumina-forming systems. ...................................................5

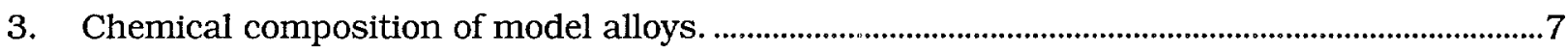

4. Estimated scale thicknesses of samples after exposure in air for 200 and $500 \mathrm{~h} . . . . . . . . . . . . . . . . .7$

5. Mechanical properties of materials used at room temperature..................................................

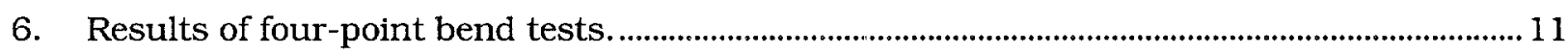

7. Residual stresses in oxide layer and alloy after oxidation at $1000^{\circ} \mathrm{C}$ and cooling to room temperature.

8. Residual stresses in oxide layer with thickness of $5 \mu \mathrm{m}$ and in the alloy after exposure at 1000 and $1200^{\circ} \mathrm{C}$ and cooling to room temperature. 


\title{
Spallation Studies on Alumina-Forming Model Alloys
}

\author{
T. Rieck, S. Majumdar, and K. Natesan \\ Energy Technology Division \\ Argonne National Laboratory \\ Argonne, IL 60439
}

\begin{abstract}
Experimental and analytical studies were conducted on the spallation behavior of alumina oxide scales on two Ni-based model alloys and one Fe-based model alloy. Oxide thicknesses of up to 5.0 $\mu \mathrm{m}$ were successfully grown on the $\mathrm{Ni}$ - based and Fe-based alloys, respectively, at an oxidation temperature of up to $1200^{\circ} \mathrm{C}$. Four-point bend tests were conducted on these specimens at room temperature and at $1000^{\circ} \mathrm{C}$ to determine the critical strain energy release rates for delamination of oxide scales.
\end{abstract}

\section{Introduction}

A key to the success of a high-temperature alloy in corrosive environments is development of a protective oxide scale, such as $\mathrm{Al}_{2} \mathrm{O}_{3}, \mathrm{Cr}_{2} \mathrm{O}_{3}, \mathrm{NiO}$, etc., which remains adherent to the substrate under expected thermal and mechanical loadings during service. Spallation of these scales can be caused by residual stresses introduced during cool-down after fabrication, or by cyclic service temperature conditions. Integrity of the protective oxide scales is determined by the thermomechanical properties of the scale, the substrate alloy, and their interface. The development of micro and macro cracks in the oxide or at the oxide/alloy interface may eventually cause spallation of the oxide and loss of larger oxide areas. As a result, the unprotected alloy may be subjected to a high-temperature corrosive environment.1,2

Oxide scales are sometimes required to serve as thermal barrier coatings. They can also be used as bond coat materials between the substrate and the ceramic coating. An understanding of the spallation mechanism of oxide scales is a first step toward understanding the more complex phenomenon of delamination of multilayer thermal barrier coatings. In all cases, failure models need to be developed in terms of critical failure mechanisms, stress/strain modeling, and mathematical expressions that define failure criteria. ${ }^{3}$

In the present study, alumina $\left(\mathrm{Al}_{2} \mathrm{O}_{3}\right)$-forming model alloys were used to investigate the spallation behavior of oxide scales. The alloys were exposed in air for various times and temperatures to form thin protective $\mathrm{Al}_{2} \mathrm{O}_{3}$ scales. The mechanical behavior of such composite specimens was determined by four-point bend tests. Finite-element analysis (FEA) was used to analyze the behavior of the specimens after cool-down from high-temperature exposure and during the bend tests, and to model the spallation of the oxide scales. 


\section{Theoretical Background}

\subsection{Stresses in Oxide Scales}

Because of its superior resistance to oxidation and sublimation compared to, for instance $\mathrm{Cr}_{2} \mathrm{O}_{3}$, alumina scale is often used to protect high-temperature alloys. The most common form of alumina is $\alpha-\mathrm{Al}_{2} \mathrm{O}_{3}$, a very stable compound that forms above $900-950^{\circ} \mathrm{C} .4$

Stresses developed in the oxide scales of high-temperature alloys may induce buckling, cracking, and spallation of the scales, leading to the loss of their protective properties and accelerated degradation of the substrate alloys. Stresses in thin surface coatings or scales are generally of two types: those developed during scale growth (growth stresses) and those developed during cooling (thermal stresses). The first category of stresses results from lattice expansion caused by diffusion processes, while the second category results from the mismatch of the thermal expansion coefficients of the scale and the underlying alloy in the presence of changing temperature or temperature gradient. After exposure of an alloy to temperature changes, both types of stresses are superimposed. 5

Stresses during scale growth are determined by the Pilling-Bedworth Ratio (PBR), a commonly used parameter equal to the oxide-to-metal volume ratio. If the PBR is less than 1, the growth stresses are tensile and the oxide may fail to cover the metal surface effectively. However, for most technologically useful oxides, the PBR is greater than 1 (as shown in Table 1) and the growth stresses are compressive, which is conducive to forming a protective oxide scale. The PBR parameter is the only origin of stress when oxide growth takes place by the inward diffusion of oxygen through the scale and oxide formation takes place at the metal/scale interface. For alumina scales, the growth mechanisms are more complex and depend on the nature and composition of the alumina-forming alloys. Alumina could form either by anodically or cathodically controlled diffusion. At temperatures higher than $1000^{\circ} \mathrm{C}$, most scale growth occurs predominantly by anodic diffusion, while below $900^{\circ} \mathrm{C}$, cathodic diffusion tends to be predominant. ${ }^{5}$ Although the PBR is controlled by factors such as scale thickness or diffusion direction, those are among the many factors that determine the protective properties of oxide scales. The PBR is less important when oxidation occurs by the outward diffusion of metal ions because the oxide is formed at the outer free surface. ${ }^{4,5}$

Table 1. PBR of typical technical metal-oxide systems. ${ }^{4}$

\begin{tabular}{cc}
\hline Oxide & Oxide-to-metal volume ratio (PBR) \\
\hline \hline $\mathrm{Al}_{2} \mathrm{O}_{3}$ & 1.28 \\
$\mathrm{Cr}_{2} \mathrm{O}_{3}$ & 2.07 \\
$\mathrm{NiO}$ & 1.65 \\
$\mathrm{FeO}$ & 1.7 \\
$\mathrm{TiO}_{2}$ & 1.73 \\
\hline
\end{tabular}

Thermal residual stresses in a metal/oxide bilayer are created by the difference in the thermal expansion coefficients of the oxide scale and the substrate (Fig. 1). If bending is constrained, 
uniform tensile and compressive stresses are generally imposed on the metal and the oxide, respectively, away from free edges. If bending is not constrained, the bending strain, $\varepsilon$, in a multilayer strip is expressed by

$$
\varepsilon=\left(x-t_{n}\right) / r+c,
$$

where $x=t_{n}$ defines the position of the neutral axis, $r$ is the radius of curvature, and $c$ is a constant. ${ }^{6}$ The stress, $\sigma_{0}$, in the linear elastic oxide scale can be expressed by

$$
\sigma_{O}=E_{O}\left(\varepsilon-\alpha_{O} \Delta T\right) \text { for }\left(0 \leq x \leq t_{O}\right) \text {, }
$$

where to is the thickness, $\mathrm{E}_{\mathrm{O}}$ is the Young's modulus of the oxide, and $\alpha_{\mathrm{O}} \Delta \mathrm{T}$ is the thermal strain in the oxide. 6

Table 2 shows experimental data on growth stresses and residual stresses of several aluminaforming alloys. 6
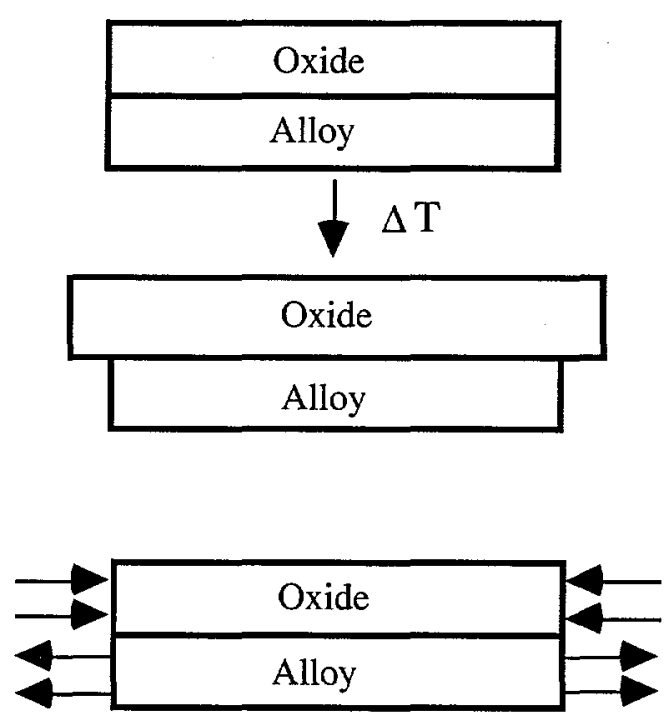

Initial

Stress free Conditon

\section{After Cooling}

$\varepsilon_{\mathrm{O}}=\alpha_{\mathrm{O}} \Delta \mathrm{T}$

$\varepsilon_{\mathrm{A}}=\alpha_{\mathrm{A}} \Delta \mathrm{T}$

Fig. 1. Alloy and oxide in stress-free initial condition. If decoupled, after cooling they would exhibit unconstrained differential shrinkage. If interfacial bond is intact, it will give rise to tensile stress in the alloy and compressive stress in the oxide. 
Table 2. Growth and residual stresses in alumina-forming systems.

\begin{tabular}{ccc}
\hline Stress Type & Alloy & Stress (MPa) \\
\hline \hline Growth stresses & FeNiCrAl, 1000 & -400 \\
& FeNiCrAlY, 1000 & -80 \\
Residual stresses at & $\mathrm{MCrAlY}, 1100^{\circ} \mathrm{C}$, & -5700 \\
room temperature & $\mathrm{FeCrAlY}, 1150^{\circ} \mathrm{C}$ & -5000 \\
& $\mathrm{NiCoCrAlY}, 1150^{\circ} \mathrm{C}$ & -70 to -300 \\
& $\mathrm{FeCrAl}, 1300^{\circ} \mathrm{C}$ & -2500 to -3000 \\
\hline
\end{tabular}

\subsection{Failure Mechanisms of Oxide Scales}

Oxide spallation typically occurs when the oxide layer is under compressive in-plane stress after cooling from oxidation temperature. Through-thickness cracks may develop in the oxide scale, followed by oxide/alloy decohesion to produce spallation. In the literature, $1,7,8$ two modes of oxide failure are discussed (Fig. 2). In mode I failure, which usually occurs when the oxide/alloy interface is strong, the initial failure of the scale is by shear cracking from a preexisting defect within the oxide scale. Subsequently, it produces wedging of the oxide scale (Fig. 2). In mode II failure, which usually occurs when the oxide/alloy interface is weak, decohesion may begin at the start of the cooling cycle. This may lead to the development of tensile cracks through the oxide thickness by a buckling mechanism (Fig. 2). If there are local regions of adhesion separated by regions of decohesion, buckling may lead to failure of the scale. However, because buckling generally requires the generation of high compressive stresses, mode I failure is the more likely mechanism of failure for most oxides. $1,7,8$

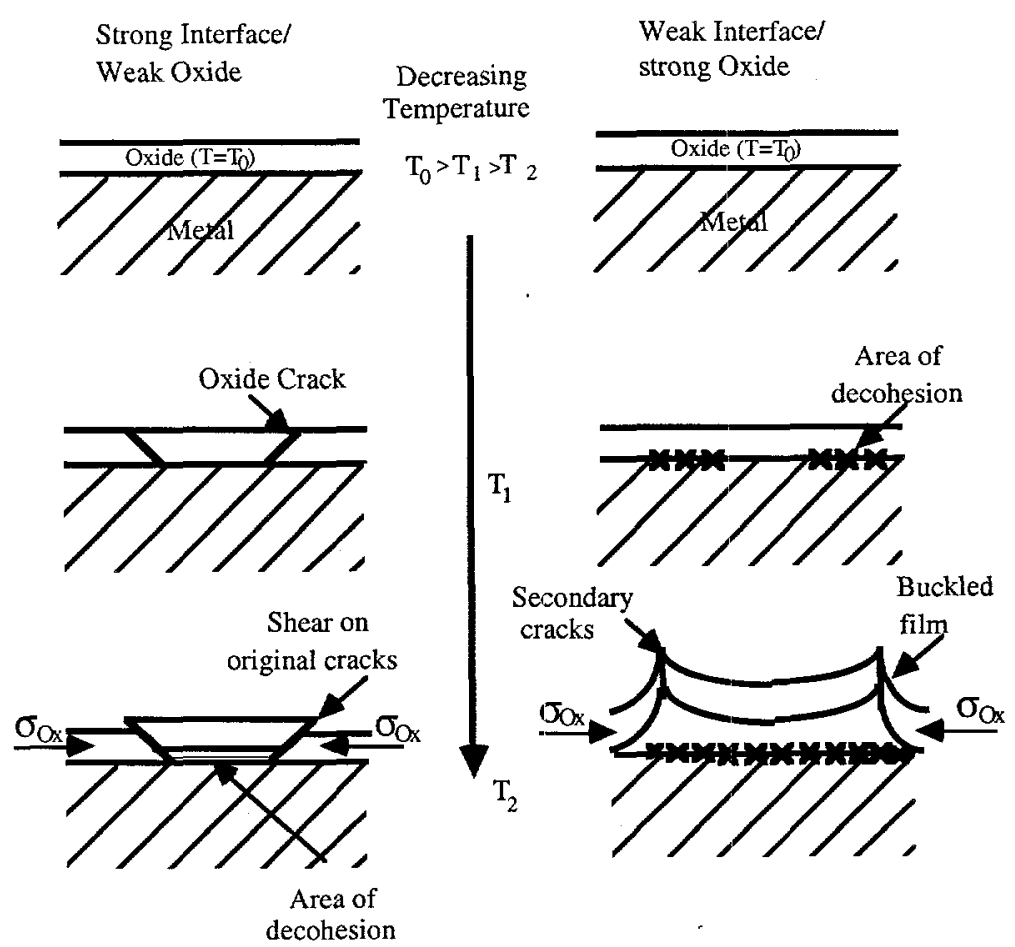

Fig. 2. Oxide spallation for mode I wedging process and mode II buckling process. 
Because decohesion of the oxide scale from the substrate generally initiates from interfacial flaws (cracks) created during either oxidation or subsequent cool-down, it can be handled by fracture mechanics. The description of the local stress and displacement field for a crack at the interface between two elastic materials is different from that in a monolithic solid. This is due to the discontinuity in elastic properties across the interface; the metal and the oxide generally have significantly different elastic constants. The singular stress field at the tip of a sharp interfacial crack between two layers depends on two nondimensional parameters, called Dundur's parameters: 9

$$
\alpha=\frac{G_{1}\left(1-v_{2}\right)-G_{2}\left(1-v_{1}\right)}{G_{1}\left(1-v_{2}\right)+G_{2}\left(1-v_{1}\right)},
$$

and

$$
\beta=\frac{1}{2}\left(\frac{G_{1}\left(1-2 v_{2}\right)-G_{2}\left(1-2 v_{1}\right)}{G_{1}\left(1-v_{2}\right)-G_{2}\left(1-v_{1}\right)}\right),
$$

where $G_{i}\left(i=1\right.$ and 2) and $v_{i}$ are the shear moduli and Poisson's ratios, respectively, of materials 1 and 2 (oxide and metal) above and below the interface. The Dundur's parameters $\alpha$ and $\beta$ measure the mismatch of elastic constants between the two materials. If the layers have the same elastic constants, $\alpha=\beta=0.9,11,12$ The stresses at the crack tip in polar coordinates $r$ and $\theta$ (Fig. 3), specialized for the crack plane $(\theta=0)$ and excluding mode III loading, can be expressed by ${ }^{9}$

$$
\left(\sigma_{\mathrm{yy}}+\mathrm{i} \sigma_{\mathrm{yx}}\right)_{\theta=0}=\frac{\mathrm{Kr}^{\mathrm{i} \varepsilon}}{\sqrt{2 \pi \mathrm{r}}}
$$

where $\mathrm{K}$ is a complex stress intensity factor. While stress intensity factors $\mathrm{K}_{\mathrm{I}}$ and $\mathrm{K}_{\mathrm{II}}$ (independent of r) characterize the amplitudes of the singularities of normal (mode I) and shear (mode II) stresses in a monolithic solid, the analogous $\mathrm{K}_{1}$ and $\mathrm{K}_{2}$ for the interfacial crack depend on the polar coordinate r.

$$
\begin{aligned}
& K_{1}(r)=\operatorname{Re}\left(K r^{i \varepsilon}\right), \\
& K_{2}(r)=\operatorname{Im}\left(K r^{i \varepsilon}\right),
\end{aligned}
$$

where Re and Im stand for the real and imaginary parts of a complex number, and the exponent $\varepsilon$ depends on Dundur's parameter $\beta^{9-11}$ as follows:

$$
\varepsilon=\frac{1}{2 \pi} \ln \left(\frac{1-\beta}{1+\beta}\right) .
$$

The corresponding strain-energy release rate $\mathrm{G}_{\mathrm{S}}$ is given by 9,13

$$
\mathrm{G}_{\mathrm{S}}=\frac{\left[\left(1-v_{1}\right) / \mathrm{G}_{1}+\left(1-v_{2}\right) / \mathrm{G}_{2}\right]|\mathrm{K}|^{2}}{4 \cosh ^{2}(\pi \varepsilon)} \text {. }
$$




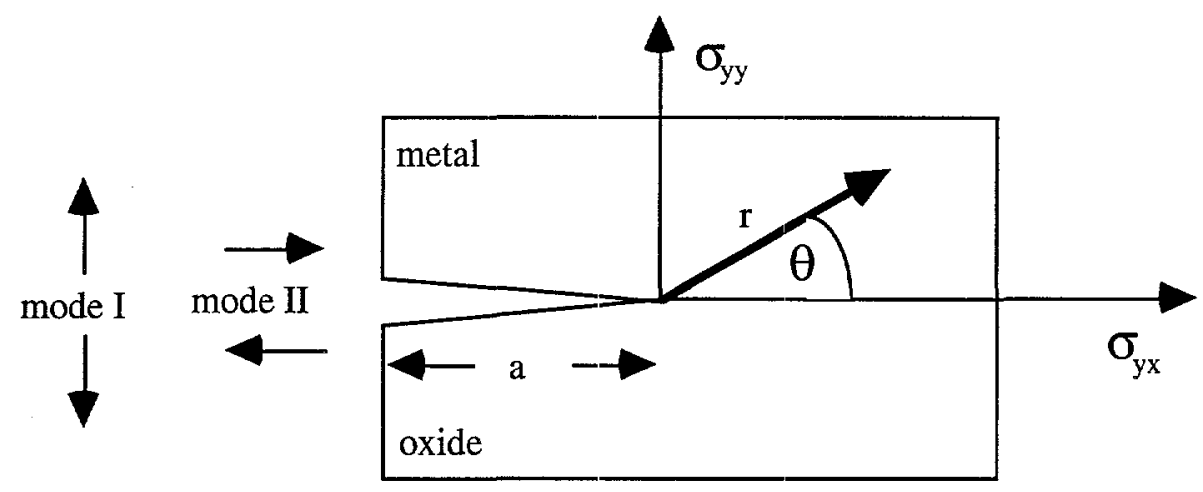

Fig. 3. Plane strain geometry of crack tip.

The failure of oxide scales can be based on either a critical strain energy release rate $\left(\mathrm{G}_{\mathrm{C}}\right)$ or on a fracture toughness $\mathrm{K}_{\mathrm{IC}}$. Experimental results for various oxide scales from Ref. 2 are shown in Fig. 4, which depicts the critical strains to tensile failure as a function of the defect size in the oxide scales, based on the experimentally determined fracture toughness values $\mathrm{K}_{\mathrm{IC}}$. The failure strain for alumina is $7.0 \times 10^{-4}$, and that for iron oxides on mild steel ranges from $1.0 \times 10^{-4}$ to $2.3 \times 10^{-4} .2$

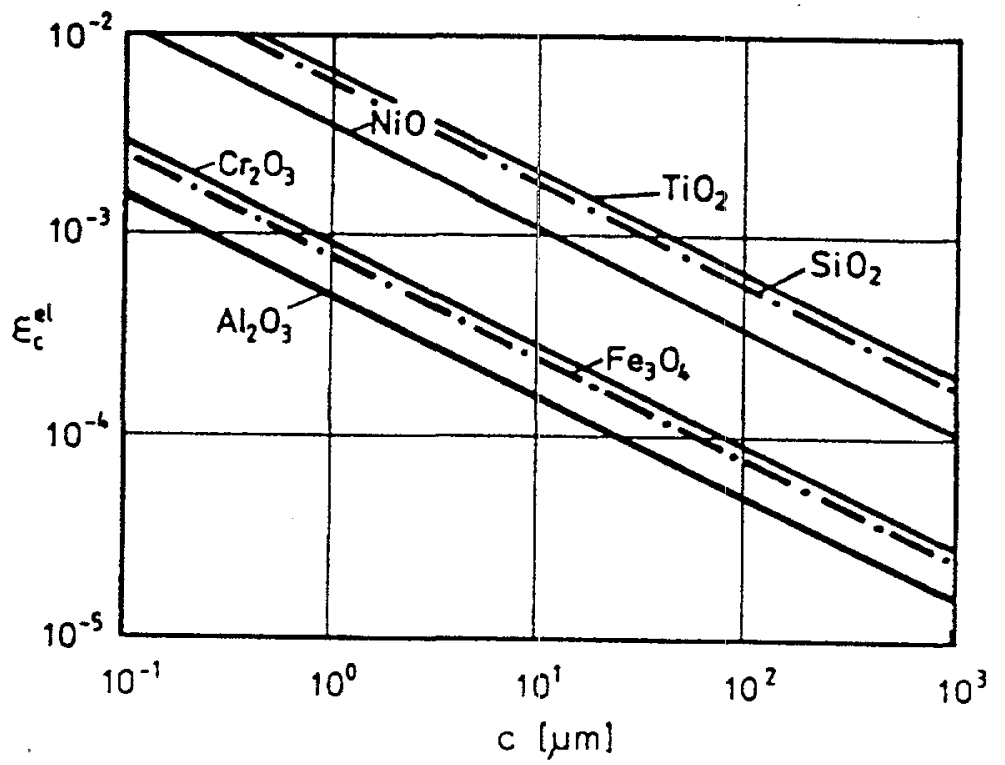

Fig. 4. Critical strains to scale failure under tensile stresses for various oxides as a function of defect size (Adapted from Ref. 2). 


\section{Experimental Work}

\subsection{Specimen and Test Conditions}

For the four-point bend tests, two Ni-based (Alloy 1 and Alloy 2) and one $\mathrm{Fe}_{3} \mathrm{Al}$-based (Alloy 3) model alloys were used. The chemical compositions of these alloys are listed in Table 3. All test specimens had a rectangular cross-section measuring $25.4 \times 4.75 \times 1.6 \mathrm{~mm}$. To minimize variability due to surface finish, all specimens were ground to 1200 grid. The samples were exposed for 200 and $500 \mathrm{~h}$ at 1000 and $1200^{\circ} \mathrm{C}$ in air and slowly cooled. For Alloys 1 and 2, the scale thicknesses (see Table 4) were calculated from the measured weight change, while for Alloy 3 , the scale thicknesses (Table 4) were calculated by the parabolic rate constant for oxidation $\mathrm{k}_{\mathrm{p}}=1.9 \cdot 10^{-6}$ $\mathrm{mg}^{2} / \mathrm{cm}^{4} \mathrm{~s}\left(1000^{\circ} \mathrm{C}\right.$ in air), as reported for a similar $\mathrm{Fe}_{3} \mathrm{Al}$ alloy in Ref. 14 . Not all alumina scales survived the cool-down to room temperature. These samples, as well as those that showed some scale cracking, were not used for the bend tests.

Table 3. Chemical composition of model alloys.

\begin{tabular}{ccccc}
\hline & \multicolumn{4}{c}{ Chemical Composition (wt.\%) } \\
\cline { 2 - 5 } Model Alloy & bal. & $\mathrm{Cr}$ & $\mathrm{Al}$ & Other \\
\hline \hline Alloy 1 & $\mathrm{Ni}$ & 10.1 & 10.3 & - \\
Alloy 2 & $\mathrm{Ni}$ & 10.1 & 10.3 & $0.1 \mathrm{Y}$ \\
Alloy 3 & $\mathrm{Fe}$ & 2.2 & 15.9 & - \\
\hline
\end{tabular}

\subsection{Material Properties}

FEA requires material properties, such as Young's modulus E, Poisson's ratio $v$, and thermal expansion coefficient $\alpha$. Although data for alumina have been reported in the literature, 15,16 they were not available for the model alloys. Therefore, data from commercial alloys with similar chemical compositions were used in our analyses. The properties of Superalloy IN-16217 were used for those of the Ni-based model Alloys 1 and 2, and the properties of Alloy A-286 18 were used for those of the Fe-based Alloy 3. Mechanical properties for these materials at room temperature are listed in Table 5.

Table 4. Estimated scale thicknesses of samples after exposure in air for 200 and $500 \mathrm{~h}$.

\begin{tabular}{ccccc}
\hline & \multicolumn{4}{c}{ Temperature } \\
\cline { 2 - 5 } Model Alloy & \multicolumn{2}{c}{$1000^{\circ} \mathrm{C}$} & \multicolumn{2}{c}{$1200^{\circ} \mathrm{C}$} \\
& $200 \mathrm{~h}$ & $500 \mathrm{~h}$ & $200 \mathrm{~h}$ & $500 \mathrm{~h}$ \\
\hline \hline Alloy 1 & $1.5 \mu \mathrm{m}$ & $2 \mu \mathrm{m}$ & no scale survived \\
Alloy 2 & $1.5 \mu \mathrm{m}$ & $2 \mu \mathrm{m}$ & $5 \mu \mathrm{m}$ & $5 \mu \mathrm{m}$ \\
Alloy 3 & $3 \mu \mathrm{m}$ & $3 \mu \mathrm{m}$ & $5 \mu \mathrm{m}$ & $5 \mu \mathrm{m}$ \\
\hline
\end{tabular}


Table 5. Mechanical properties of materials used at room temperature.

\begin{tabular}{cccccc}
\hline \multirow{2}{*}{ Alloy } & & $\begin{array}{c}\text { Young's modu- } \\
\text { lus E (GPA) }\end{array}$ & $\begin{array}{c}\text { Poisson's ratio } \\
v\end{array}$ & $\begin{array}{c}\text { Therm. expan. } \\
\text { coeff. } \alpha\left(\mathrm{K}^{-1}\right)\end{array}$ & Ref. \\
\hline \hline Alloy 1 + 2 & IN-162 & 195 & 0.3 & $13.0 \times \cdot 10^{-6}$ & 17 \\
Alloy 3 & A-286 & 201 & 0.3 & $17.6 \times \cdot 10^{-6}$ & 18 \\
Alumina & - & 385.8 & 0.245 & $7.12 \times \cdot 10^{-6}$ & 15,16 \\
\hline
\end{tabular}

\subsection{Oxidation Behavior of Tested Alloys}

The in-air oxidation behavior of the Ni-based model alloys were investigated at 1000 and $1200^{\circ} \mathrm{C}$ under cyclic-temperature (between high temperature and room temperature) conditions so that all sides of the specimens were oxidized. To produce samples with different microstructures, they were annealed 1 or $50 \mathrm{~h}$ in $\mathrm{H}_{2}$ before oxidation. Figure 5 shows the oxidation behavior, as measured by weight change, at $1000^{\circ} \mathrm{C}$, and Fig. 6 shows the same data measured at $1200^{\circ} \mathrm{C}$. The specimens in these tests were oxidized at high temperature for various cumulative exposure times, cooled to room temperature and their weight losses measured, reoxidized at temperature, and so on. The alloys have significantly better corrosion behavior at $1000^{\circ} \mathrm{C}$ than at $1200^{\circ} \mathrm{C}$. The alloy with yttrium addition appears to grow an adherent alumina scale, while the alloy without yttrium suffers weight loss after 200-300 hours exposure. This weight loss could be caused by spallation of the scale. However, because the net weight change is not negative, the scales seem to be partially adherent and may even be protective for the alloy without yttrium.

At $1200^{\circ} \mathrm{C}$, measured weight change curves are worse for both alloys. After $200 \mathrm{~h}$, even the alloy with yttrium shows spallation behavior. The weight change of the alloy without yttrium is always negative, indicating that the oxide scales spall from the beginning of exposure. In this case, no protective oxide scale is formed. In all cases at $1200^{\circ} \mathrm{C}$, annealing time has a small influence on weight change. The alloy with yttrium addition performs slightly better than that without yttrium. Yttrium has a beneficial influence on oxidation behavior because it produces a more adherent and robust alumina scale on the alloy.

Typical surfaces of the exposed samples are shown in Fig. 7. In contrast to the specimens of Figs. 5 and 6 , these specimens were subjected to only one cycle of oxidation (high temperature to room temperature). As a result, weight losses in these tests were expected to be much lower than those in the cyclic oxidation exposure (Figs. 5 and 6) tests. The high values of calculated residual stresses (see Tables 7 and 8), as well as in the literature data (see Table 2), are consistent with the observed loss of oxide scales after cooling. Note that the oxide scales on Alloy 2 (Figs. 7), which adhere to the substrate when their thicknesses are $\leq 2 \mu \mathrm{m}$, show cracking and signs of spallation when scale thickness is $5 \mu \mathrm{m}$. 


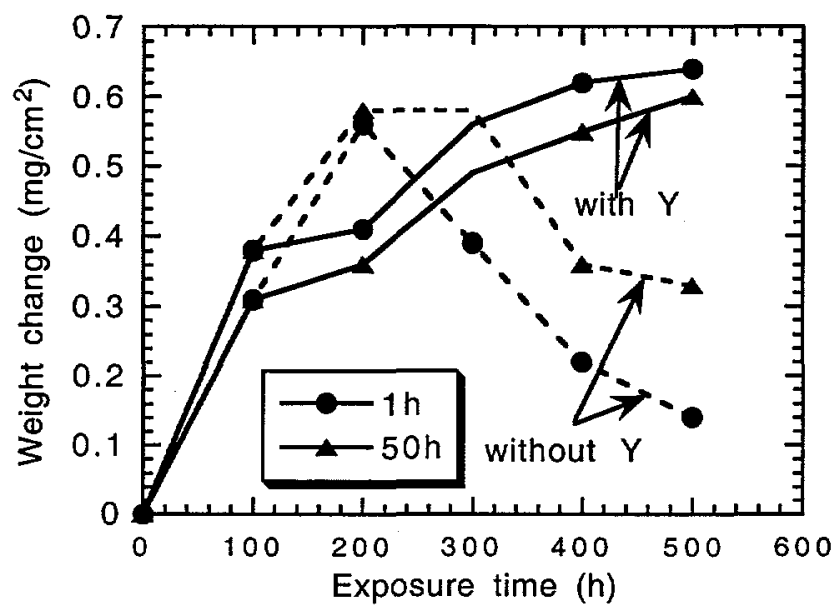

Fig. 5. Cyclic oxidation behavior of Ni-based model alloys 2 (with $Y$ ) and 1 (without $Y$ ) after 500-h exposure at $1000^{\circ} \mathrm{C}$ in air. Samples were annealed in $\mathrm{H}_{2}$ for 1 or $50 \mathrm{~h}$.

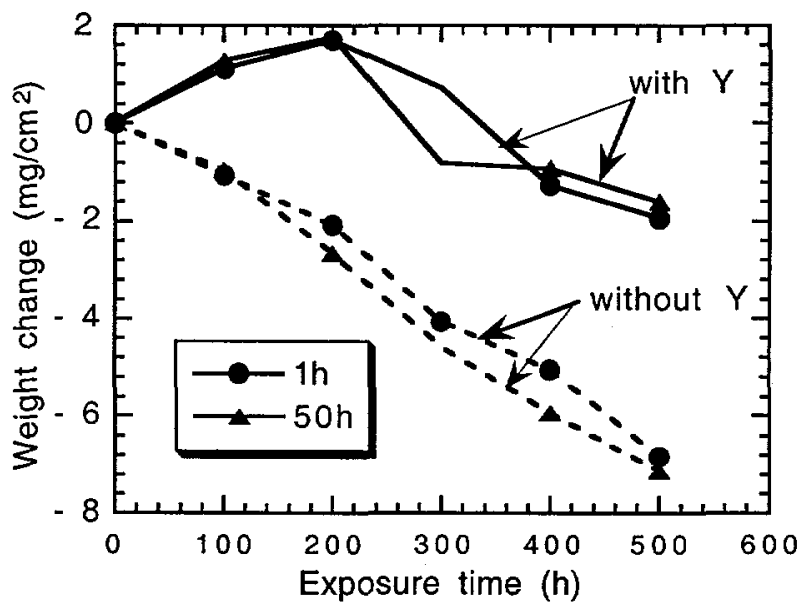

Fig. 6. Cyclic oxidation behavior of Ni-based model alloys at $1200^{\circ} \mathrm{C}$ in air. Samples were annealed in $\mathrm{H}_{2}$ for 1 or $50 \mathrm{~h}$. (With $Y=$ Alloy 2; without $Y=$ Alloy 1). 


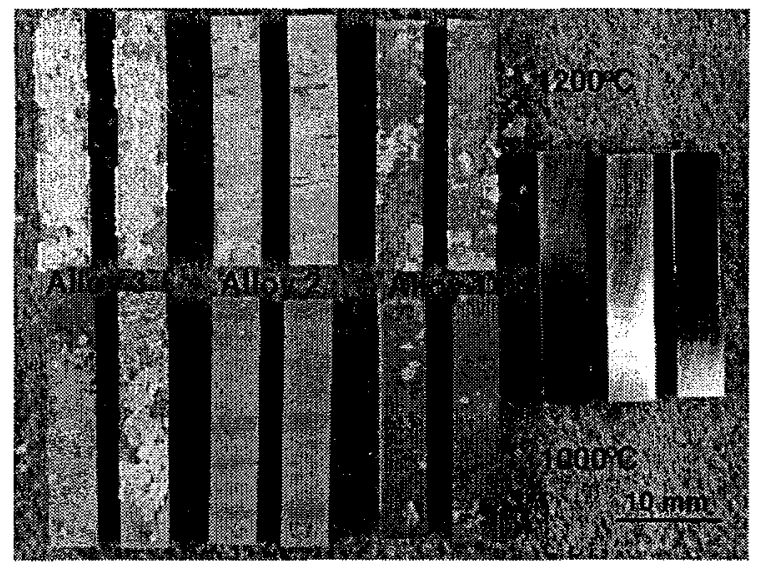

(a)

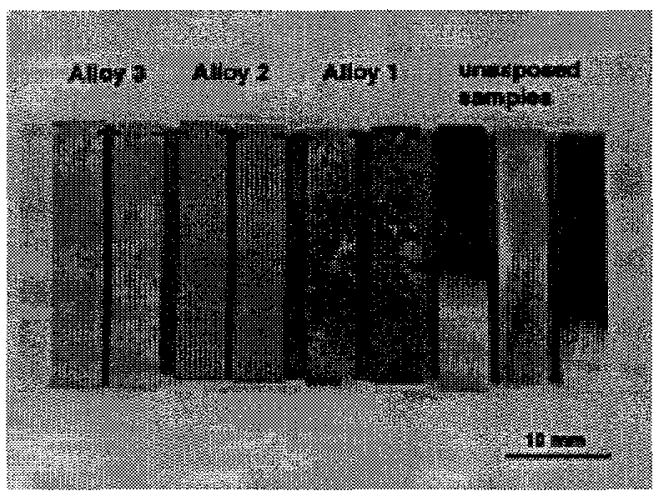

(b)

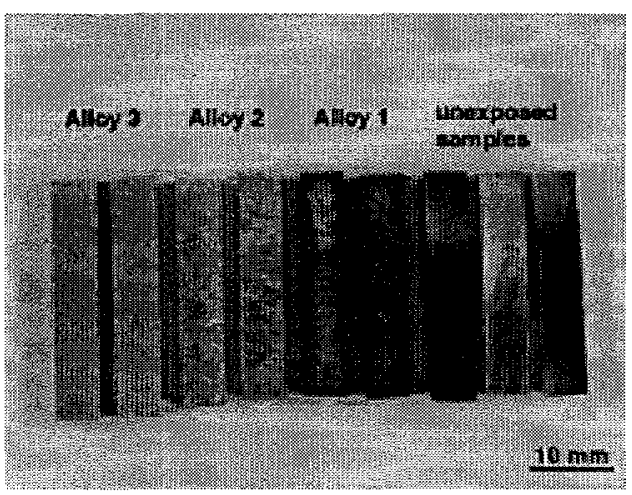

(c)

Fig. 7. Surfaces of specimens oxidized in air for (a) $200 \mathrm{~h}$ at 1000 and $1200{ }^{\circ} \mathrm{C}$, (b) $500 \mathrm{~h}$ at $1000^{\circ} \mathrm{C}$, and (c) $500 \mathrm{~h}$ at $1200^{\circ} \mathrm{C}$. For reference, ground unoxidized samples are also shown.

\subsection{Four-Point Bend Tests}

Because the oxide scales survived exposure for $200 \mathrm{~h}$ at $1000^{\circ} \mathrm{C}$ in all three alloys and for $500 \mathrm{~h}$ at $1000^{\circ} \mathrm{C}$ in Alloys 2 and 3, these specimens were tested in four-point-bending to study their failure behavior. The four-point bend tests were conducted in an Instron (Model 1125) tensile testing machine at room temperature and at $1000^{\circ} \mathrm{C}$. The elevated-temperature tests were carried out in a vacuum chamber between $10^{-9}$ and $10^{-11} \mathrm{bar}$. Crosshead speed for all tests was $0.05 \mathrm{~mm} / \mathrm{min}$. A ceramic device was used to hold and load the specimens. The loading points are shown in Fig. 8. Relative slippage was allowed at all loading points. For the oxidized samples, the tests were interrupted at specified load steps, which ranged from $98.1 \mathrm{~N}$ at room temperature to $49.05 \mathrm{~N}$ at elevated temperature. After each loading step, the tension and compression sides of the samples were inspected with an optical microscope. The tests were terminated either when first cracking was detected in the bulk material or when the specimens attained a maximum bending displacement of $\approx 2-3 \mathrm{~mm}$. 


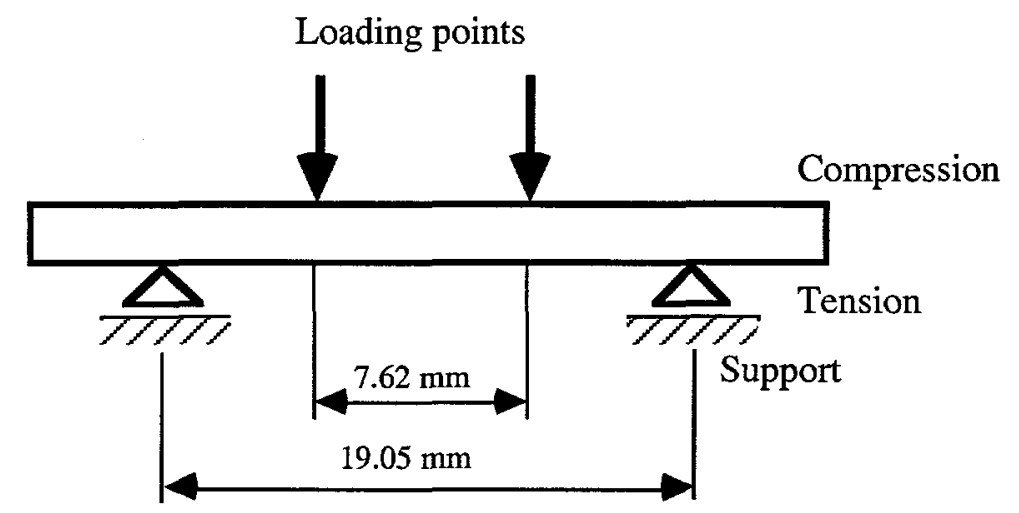

Fig. 8. Geometry and loading configuration of four-point bend tests.

Table 6 shows the results of the four-point-bend tests. The bending stresses in the oxide scale (excluding residual stress) were calculated at the load when first cracking in the scale was detected or at the maximum load for specimens in which the scale did not crack. The alumina scales of Alloys 1 and 2 experienced cracking during the room-temperature tests at comparable stresses. The specimen of Alloy 2 with a $2-\mu \mathrm{m}$-thick scale cracked at a lower stress. This cannot be explained by residual stress argument, because the residual stresses in the specimens with $1.5-\mu \mathrm{m}$ - and $2-\mu \mathrm{m}$ thick scales are almost equal (see Table 7). It is possible that the lower failure stress in the thicker scale was the result of a larger defect or higher defect density in the scale. In the remainder of the specimens, the oxides either did not crack or did not spall before interruption of the tests and are denoted by "no failure" in Table 6 . In contrast to the room-temperature tests, none of the specimens tested at $1000^{\circ} \mathrm{C}$ showed any sign of spallation or oxide cracking, possibly because the residual stresses were drastically reduced at $1000^{\circ} \mathrm{C}$. The oxide scale on alloy 3 did not crack at room temperature. However, at $1000^{\circ} \mathrm{C}$, the bending deflection limit was reached at very low loads, indicating that this alloy is quite weak at elevated temperatures.

Table 6. Results of four-point bend tests. Calculated bending stresses exclude contributions from residual stresses.

\begin{tabular}{ccccc}
\hline & $\begin{array}{c}\text { Calc. Scale } \\
\text { Thickness } \\
{[\mu \mathrm{m}]}\end{array}$ & Test conditions & Scale failure & $\begin{array}{c}\text { Bend stress in } \\
\text { scale [MPa] }\end{array}$ \\
\hline \hline 1 & 1.5 & $\mathrm{RT}$ & failure & $\pm \mathbf{8 2 9 . 0 5}$ \\
& 1.5 & $1000^{\circ} \mathrm{C} /$ Vacuum & no failure & \pm 289.91 \\
2 & 1.5 & $\mathrm{RT}$ & failure & $\pm \mathbf{7 6 3 . 5 1}$ \\
& 1.5 & $1000^{\circ} \mathrm{C} /$ Vacuum & no failure & \pm 340.53 \\
& 2 & $\mathrm{RT}$ & failure & $\pm \mathbf{5 0 3 . 4 6}$ \\
& 2 & $1000^{\circ} \mathrm{C} /$ Vacuum & no failure & \pm 502.36 \\
3 & 3 & $\mathrm{RT}$ & no failure & \pm 475.80 \\
& 3 & $1000^{\circ} \mathrm{C} /$ Vacuum & no failure & \pm 6.63 \\
& 3 & $\mathrm{RT}$ & no failure & \pm 829.89 \\
& 3 & $1000^{\circ} \mathrm{C} /$ Vacuum & no failure & \pm 9.95 \\
\hline
\end{tabular}


Specimen surfaces at first cracking or spallation of the oxide on Alloys 1 and 2 are shown in Figs. 9-11. The optical microscope photomicrographs were taken at the point of first cracking, and the SEM images are higher-magnification pictures of the failed areas. Note that the compression sides of the samples have larger spalled areas than do the tension sides, probably because the residual stresses and the bending stresses add in the compression sides. The tension side in Fig. 9 shows evidence of $45^{\circ}$ shear cracking. The SEM pictures for both sides (tension and compression) in Fig. 9 also shows effects of buckling, which is indicative of the importance of compressive stresses on oxide failure. The presence of spalled areas around the crack in Fig. 10 indicates that spallation of the oxide scales occurred before the substrate cracked. Spallation of the oxide scale starting at the edge, as shown in Fig. 11, is consistent with the presence of a stress singularity at this location. 
tension

compression
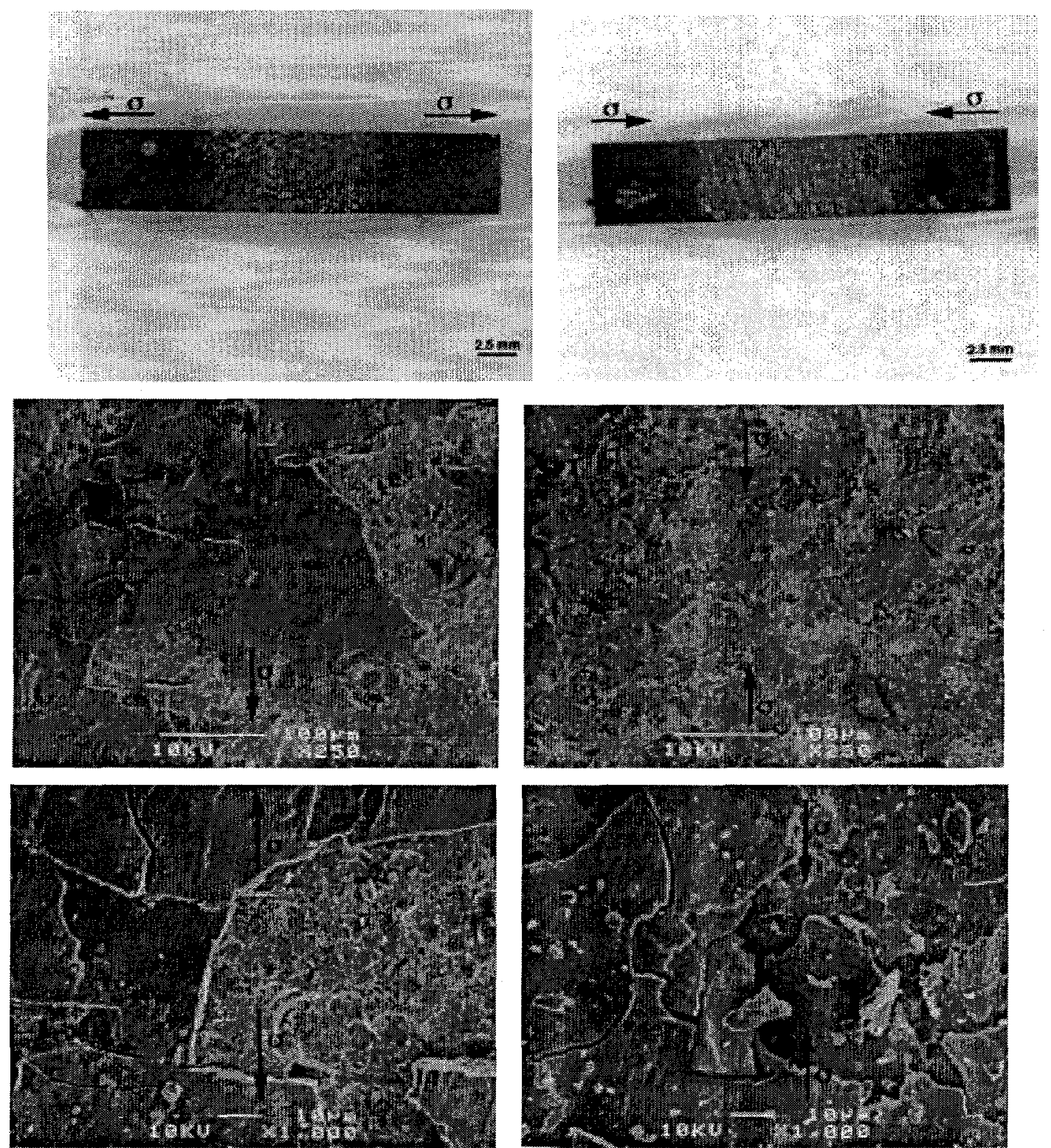

Fig. 9. Surface of Alloy 1 after bend test at room temperature under stress condition of $829.05 \mathrm{MPa}$. Scale thickness was $1.5 \mu \mathrm{m}$. 
tension
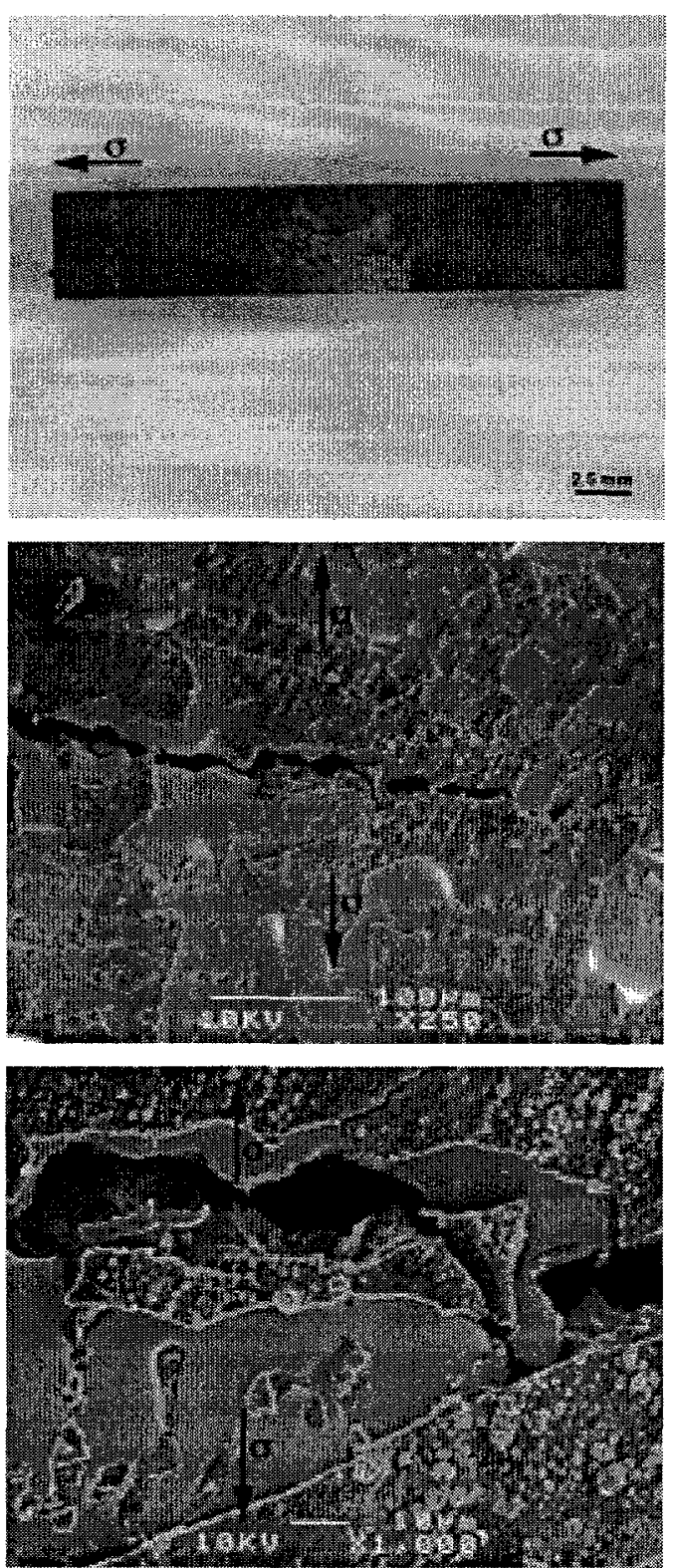

compression
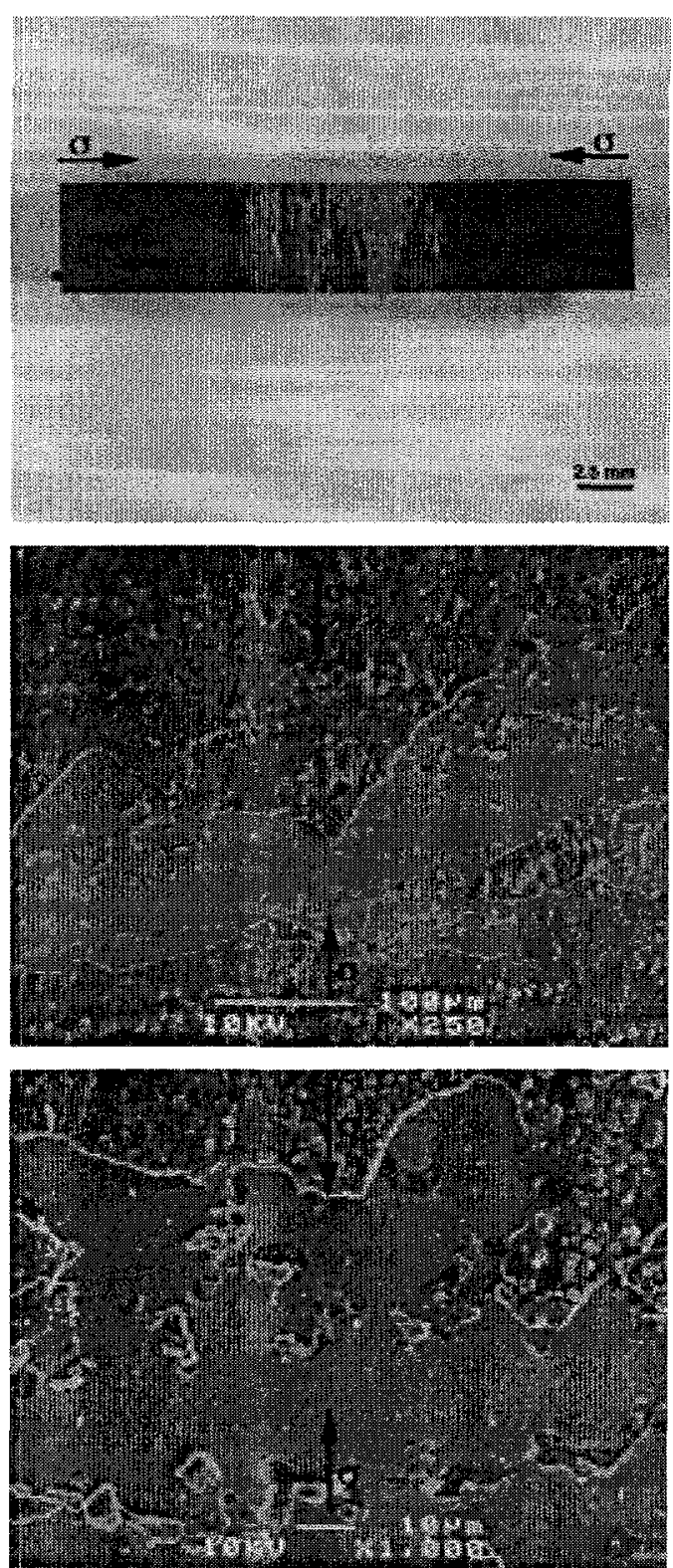

Fig. 10. Surface of Alloy 2 with 1.5- $\mu$ m-thick oxide scale after bend test at room temperature under stress condition of $763.51 \mathrm{MPa}$. 
tension
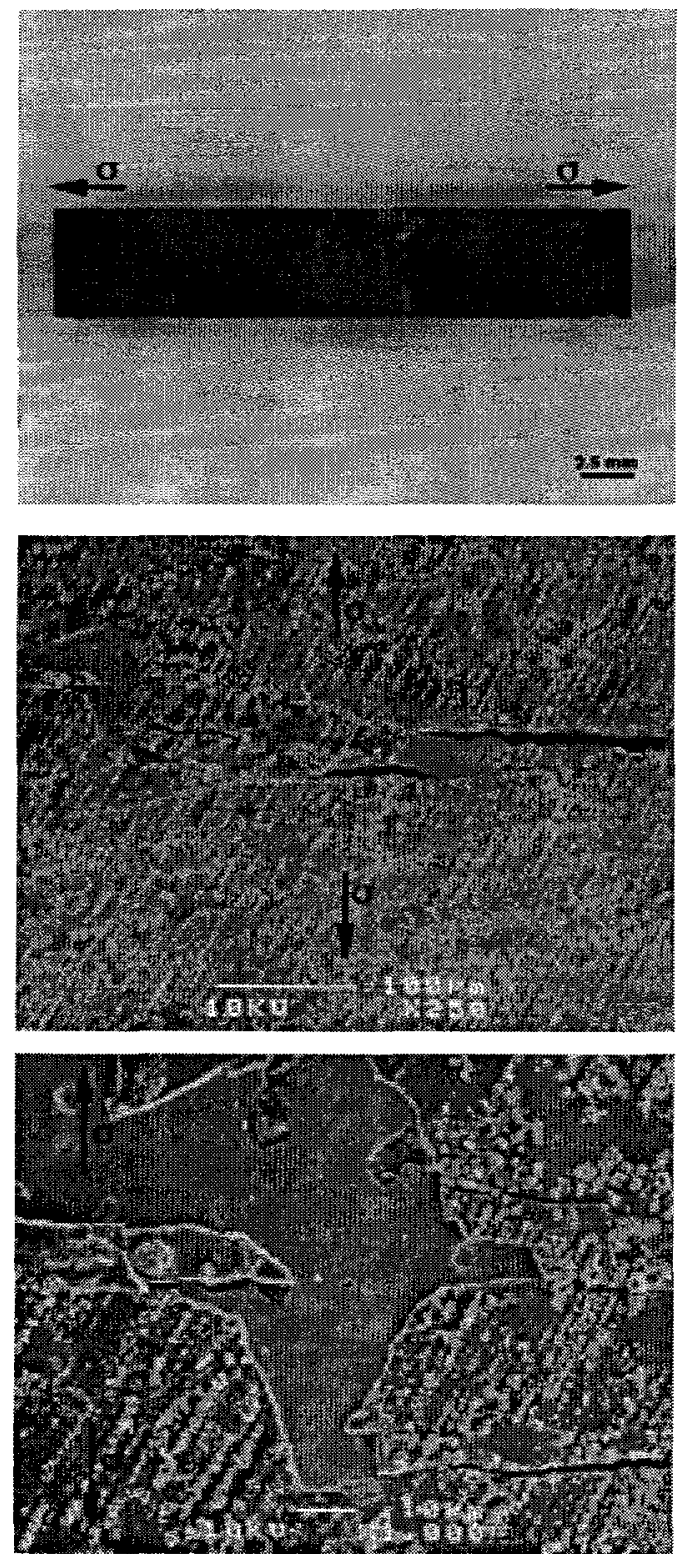

compression
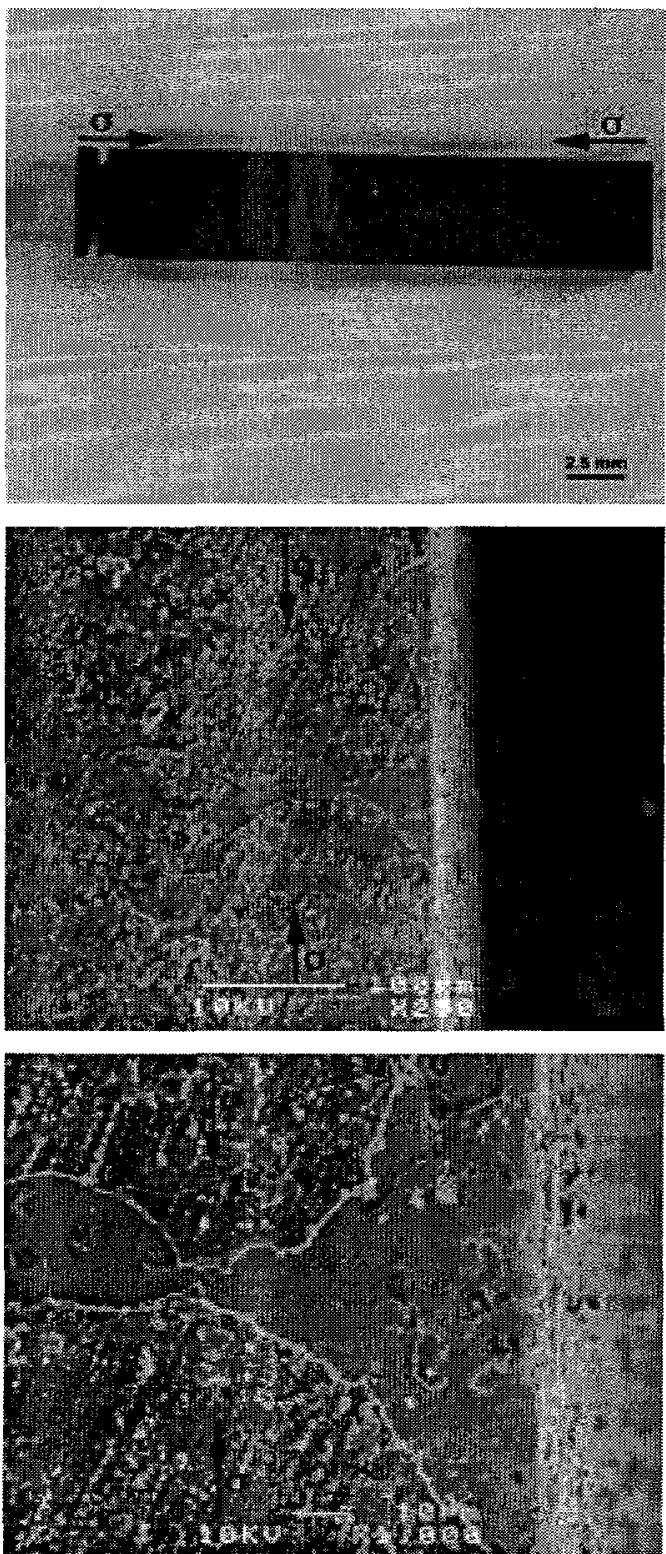

Fig. 11. Surface of Alloy 2 after bend test at room temperature under stress condition of $503.43 \mathrm{MPa}$. Alumina scale was $2.0 \mu \mathrm{m}$ thick. 


\section{Finite-Element Analysis}

\subsection{Finite-Element Models}

The finite-element analysis (FEA) was carried out with two different models in the ANSYS program to simulate the four-point bend loading. The first model was used to calculate stresses (including residual) in an oxidized sample without cracks in the oxide scale. A two-dimensional eight-noded multilayer structural shell element (shell91) was used for this purpose. Because of symmetry, only one-half of the specimen was modeled. The mesh used for analysis and the boundary conditions are shown in Fig. 12. To determine the effects of oxide cracking, interfacial cracking was modeled as a worst-case scenario with a different finite-element mesh (Fig. 13); for clarity, not all of the elements are shown in Fig. 13. A two-dimensional, eight-node structural element (plane82) was used in this case. The crack is located in the constant-bending-moment region lying between the inner loading points. The crack tip was modeled by the triangular shape of this element, which was constructed by merging two corner nodes and one midside node of the eight nodes. As before, only one-half of the beam was analyzed, by using a mesh with $\approx 15,000$ nodes. To ensure that a sufficient number of elements was located in the K-dominant region at the crack tip, the first set of elements around the crack tip was within $h / 320\left(10^{-3}\right.$ to $\left.10^{-4}\right)$ and the thickness-tocrack-tip ratio was $h_{2} / a=0.033\left(10^{-2}\right)$, where $h$ is the thickness of the beam; $h=0.2 \mathrm{~mm}$ and $h_{2}$ is the alloy thickness, $h_{2}=0.1$ ). These dimensions are in line with recommended values in Refs. 11 and 13. One other crack location (a crack intersecting the lateral free surface) was also modeled. In both cases, the same crack-tip mesh as that for the interface crack was used. To determine the crack driving force or the stress intensity factor $\mathrm{K}$, the strain-energy release rate was calculated (see Eq. 9).

For cracks in linear elastic materials, the strain-energy release rate $\mathrm{G}_{\mathrm{S}}$ was calculated by the method of virtual crack extension. For neighboring cracks of length a and a+da, Gs can be approximated from the forward difference

$$
\mathrm{G}_{\mathrm{S}}=-\frac{\mathrm{U}(\mathrm{a}+\Delta \mathrm{a})-\mathrm{U}(\mathrm{a})}{\mathrm{B} \Delta \mathrm{a}}
$$

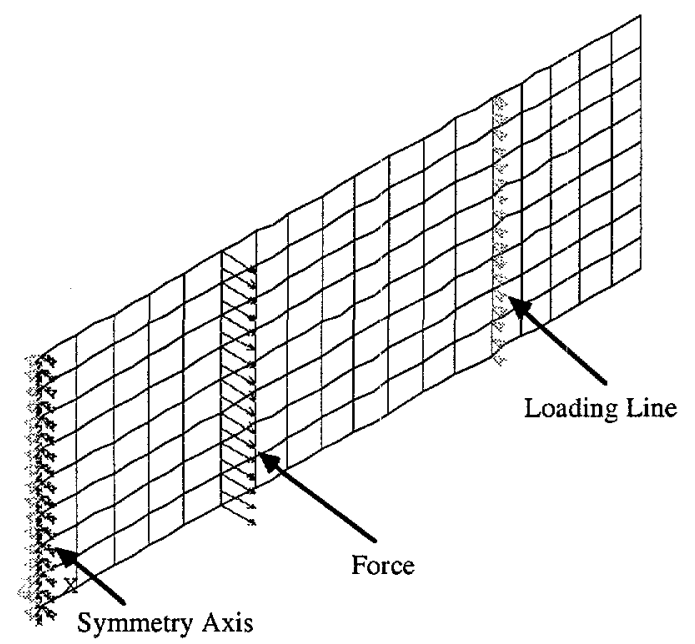

Fig. 12. Mesh and boundary conditions used in finite-element calculation to calculate stresses in oxidized samples. 


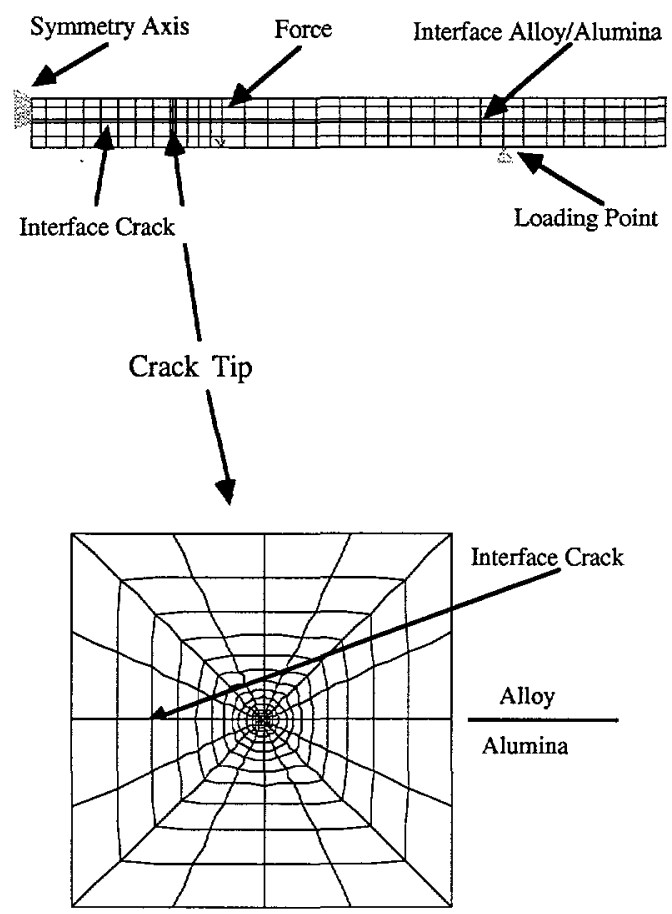

Fig. 13. Mesh and boundary condition of sample with interface crack.

where $U$ is potential energy and $B$ is specimen thickness. 19 The crack-length increment was modeled by meshes with crack lengths of $3.0,3.05$, and $3.1 \mathrm{~mm}$. Strain-energy release rate was calculated with the ANSYS postprocessor.

\subsection{FEA Results for Bend Tests}

Stresses in the alumina scale for the four-point bend tests (without crack) were calculated with the residual stresses excluded. Figures 14 and 15 show spatial distribution of the average bending stresses in each oxide layer as a function of oxide thickness for all three alloys. The average bending stresses were calculated from the stresses in the top and bottom surfaces of each layer. To facilitate the application of the results to other loading cases, the stresses were normalized by the applied load. All curves show the expected constant stress behavior between the inner loading points. Between the point of application of the load and the support, the stresses decreased linearly, reaching a zero value at the support. The results show that for the thicknesses considered, oxide scale thickness has little influence on bending stresses, and that stresses in the Ni-based alloys and the Fe-based alloy are similar.

\subsection{Effects of Residual Stresses}

Residual stresses after cooling were calculated by FEA for the Ni- or Fe-based model alloy and alumina. Because of the difference in thermal expansion coefficients in this system, compressive stress in the scale and tensile stress in the alloy are expected (see Fig. 1). This may have a significant impact on the failure mode of the oxide scale, because while compressive stresses could increase the load required to crack the oxide scales, high compressive stresses could cause buckling. 


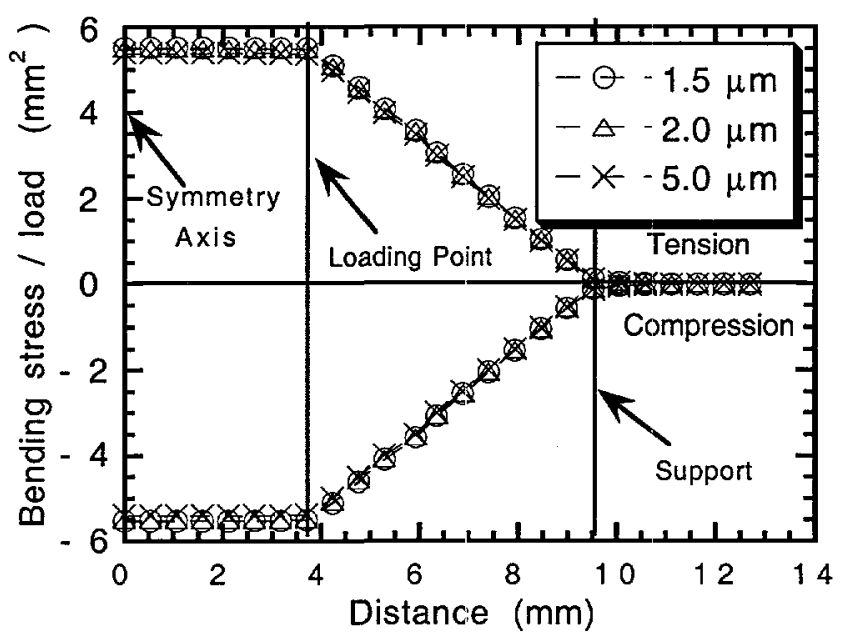

Fig. 14. Normalized bending stress in oxide scale with different thicknesses of Alloys 1 and 2.

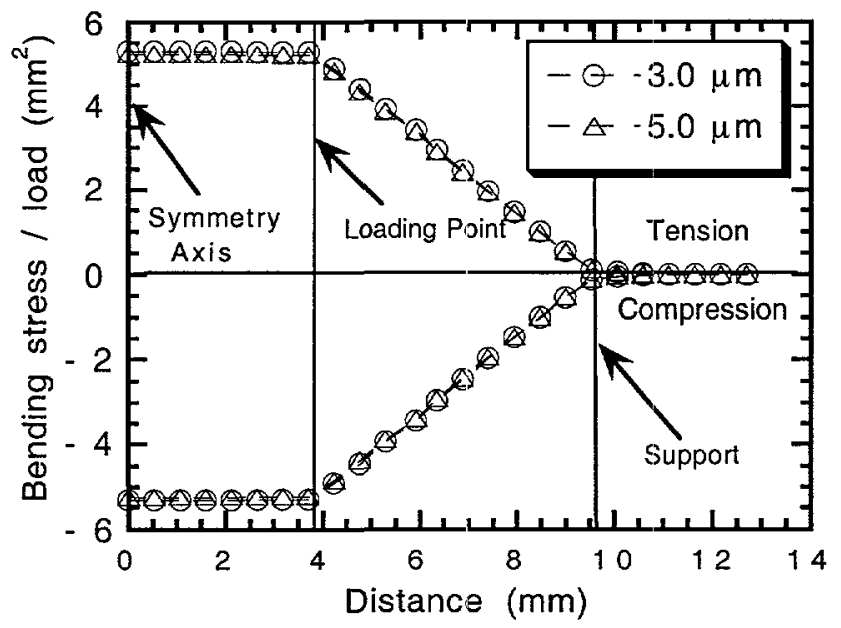

Fig. 15. Normalized bending stress in oxide scale with different thicknesses of Alloy 3.

Residual stresses (away from the free edge) in the oxide layer and in the alloy after oxidation at $1000^{\circ} \mathrm{C}$ and cooling to room temperature are shown in Table 7. Because of the thickness difference, high compressive stresses are produced in the oxide layers, whereas low tensile stresses are seen in the alloys. The stresses are constant along the length of the specimen away from the free edge. Calculated values of the residual stresses are comparable to measured values (see Table 2) reported elsewhere. 6 Because of a larger mismatch with the thermal expansion coefficient of alumina, the residual stresses in the Fe-based alloy are higher than those in the Ni-based alloys. Table 8 shows the calculated residual stresses after a cool-down from two different exposure temperatures. As expected, cooling from $1200^{\circ} \mathrm{C}$ causes much higher stresses in both alloys than does cooling from $1000^{\circ} \mathrm{C}$. It should be emphasized that these high compressive stresses are calculated values that an oxide layer by itself could never sustain because of buckling or shear failure. 
Table 7. Residual stresses in oxide layer and alloy after oxidation at $1000^{\circ} \mathrm{C}$ and cooling to room temperature.

\begin{tabular}{cccc}
\hline Alloy & $\begin{array}{c}\text { Oxide thickness } \\
(\mu \mathrm{m})\end{array}$ & $\begin{array}{c}\text { Stress in oxide } \\
(\mathrm{MPa})\end{array}$ & $\begin{array}{c}\text { Stress in alloy } \\
(\mathrm{MPa})\end{array}$ \\
\hline \hline \multirow{2}{*}{$1+2$} & 1.5 & -3164.2 & 5.93 \\
& 2.0 & -3160.3 & 7.9 \\
3 & 3.0 & -5620.0 & 21.07 \\
\hline
\end{tabular}

Table 8. Residual stresses in oxide layer with thickness of $5 \mu \mathrm{m}$ and in the alloy after exposure at 1000 and $1200^{\circ} \mathrm{C}$ and cooling to room temperature.

\begin{tabular}{cccc}
\hline Alloy & $\begin{array}{c}\text { Temperature } \\
\left({ }^{\circ} \mathrm{C}\right)\end{array}$ & $\begin{array}{c}\text { Stress in oxide } \\
(\mathrm{MPa})\end{array}$ & $\begin{array}{c}\text { Stress in alloy } \\
(\mathrm{MPa})\end{array}$ \\
\hline \hline $1+2$ & 1000 & -3137.1 & 19.61 \\
3 & & -5593.4 & 34.96 \\
$1+2$ & 1200 & -3777.3 & 23.61 \\
3 & & -6734.9 & 42.10 \\
\hline
\end{tabular}

Residual stresses are highest at room temperature, while samples at elevated temperatures reach a nearly stress-free condition. If the samples with residual stresses were subjected to bending, the residual stresses would be either additive to or subtractive from the bending stresses, depending on the sign of the residual stress. An example (Fig. 16) shows that in the case of a scale with compressive residual stresses, the scale stresses are decreased in the tension side and increased in the compression side. Beyond the support and extending to the free end of the sample, only the residual stresses remain (see Table 8 ). Because of the symmetrical location of the neutral axis, the calculated residual stresses are spatially unvarying (away from the free edge) in the oxide and in the alloy. The compressive nature of the residual stresses in the oxide is expected to increase the bending moment at which oxide cracking would occur. 


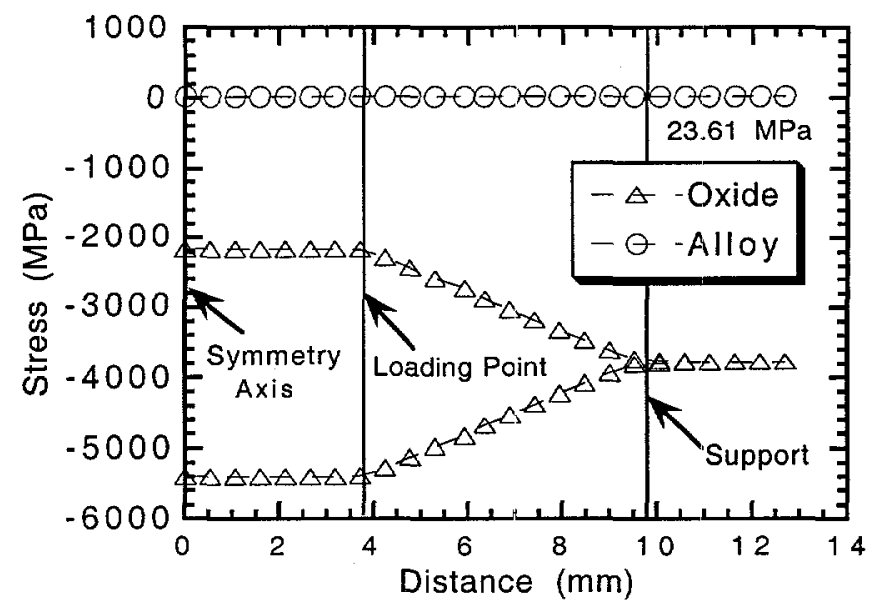

Fig. 16. Effect of residual stress on bending stress in tensile side of Alloys 1 and 2 during bend test with force of $300 \mathrm{~N}$. Scale thickness was $5 \mu \mathrm{m}$ and sample was cooled from $1200^{\circ} \mathrm{C}$ to room temperature.

\subsection{Fracture Mechanics Modeling of Spallation}

\subsubsection{Comparison of FEA with Analytical Solutions}

Oxide spallation is often related to failure or cracking at the interface of the alloy and the oxide. Therefore, a metal/oxide interface crack was modeled. If the oxide is under tension (tension side of the sample), the scale will very likely crack before interface cracking occurs. To calculate the energy release rate, the geometry shown in Fig. 17 was modeled. This model has a central transverse crack, which after passing through the thickness of the oxide scale, makes a $90^{\circ}$ turn to form an interfacial crack that was up to $6.0 \mathrm{~mm}$ long $(\mathrm{a}=3 \mathrm{~mm})$.

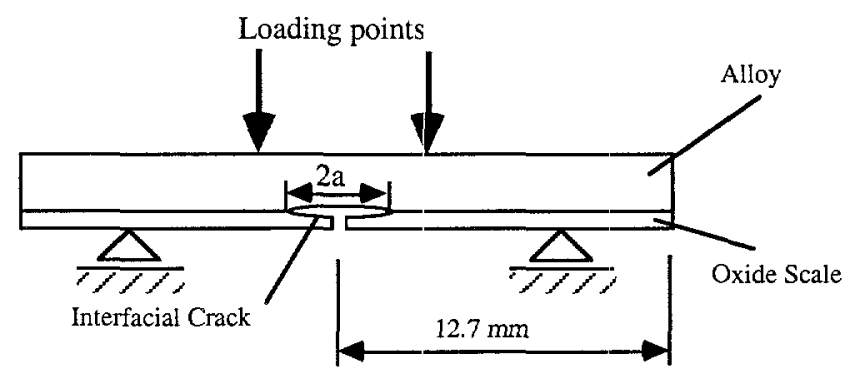

Fig. 17. Interfacial crack in bimaterial four-point bend specimen.

The model was validated by a comparison of the energy release rate with an analytical solution reported in Ref. 13. When the crack is fully contained between the central loading points, it is subjected to a constant bending moment. As a consequence, the strain energy release rate exhibits steady-state behavior, at least for interfacial cracks that are longer than the thickness of the scale. ${ }^{13}$ The steady-state value Gss can be calculated analytically from a difference in the strain energy of an uncracked and a cracked beam. The steady-state energy release rate can be expressed in terms of the applied bending moment $\mathrm{M}$ as 


$$
\mathrm{U}=\frac{\left(1-\mathrm{v}^{2}\right) \mathrm{M}^{2}}{2 \mathrm{EI}},
$$

where $U$ is the strain energy per unit cross section and $I$ is the second moment of area per unit width. The strain energy release rate reduces to

$$
\mathrm{G}_{\mathrm{ss}}=\frac{\mathrm{M}^{2}\left(1-v_{2}^{2}\right)}{2 \mathrm{E}_{2}}\left(\frac{1}{\mathrm{I}_{2}}-\frac{\lambda}{\mathrm{I}_{\mathrm{C}}}\right) \text {, }
$$

where

$$
\lambda=\frac{E_{2}\left(1-v_{1}^{2}\right)}{E_{1}\left(1-v_{2}^{2}\right)},
$$

and subscripts $\mathrm{c}$ and 1 refer to the scale, while subscript 2 refers to the alloy. $M$ is the bending moment per unit width $\mathrm{M}=\mathrm{Pl}$, with $\mathrm{P}$ the total load and 1 the distance between the load point and the support,

$$
I_{c}=\frac{h_{1}^{3}}{12}+\frac{\lambda h_{2}^{3}}{12}+\frac{\lambda h_{1} h_{2}\left(h_{1}+h_{2}\right)^{2}}{4\left(h_{1}+\lambda h_{2}\right)},
$$

and

$$
\mathrm{I}_{2}=\frac{\mathrm{h}_{2}^{3}}{12}
$$

where $h_{1}$ and $h_{2}$ are the thicknesses of the oxide layer and the alloy. Normalized strain energy release rate is given by 13

$$
\frac{\mathrm{G}_{\mathrm{SS}} \cdot \mathrm{E}_{2} \cdot \mathrm{h}^{3}}{\mathrm{M}^{2}\left(1-v_{2}^{2}\right)} \text {. }
$$

A comparison between the normalized strain energy release rates as calculated by Eq. 12 (analytical solution) and by FEA is shown in Fig. 18 for two ratios of Young's modulus. Reasonable agreement between the analytical and FEA solutions is observed, although the agreement improves with lower thickness ratio and higher Young's modulus ratio. The higher the Young's modulus ratio, the lower the strain energy release rate. Similar behavior was reported in Refs. 11 and 13, although the numerical values of the strain energy release rate differed from the current results because of the difference in geometry.

Figures 19a-b show strain energy release rates for two crack lengths. In Fig. 19a, the steadystate strain energy release rates are approximately independent of crack length. The lower the thickness ratio, the lower the difference between the analytical and the FEA solutions for both crack lengths. In Fig. 19b, the strain energy release rate for a crack of length $2 a=6 \mathrm{~mm}$ is computed by the virtual crack extension method, with $\Delta \mathrm{a}=0.05 \mathrm{~mm}$, and is compared with that obtained earlier to show that the two approaches give almost identical strain energy release rates. The good agreement between these two FEA solutions and the analytical solution gave us confidence in using the current finite-element model to calculate the strain energy rates for the alloy/oxide systems. 


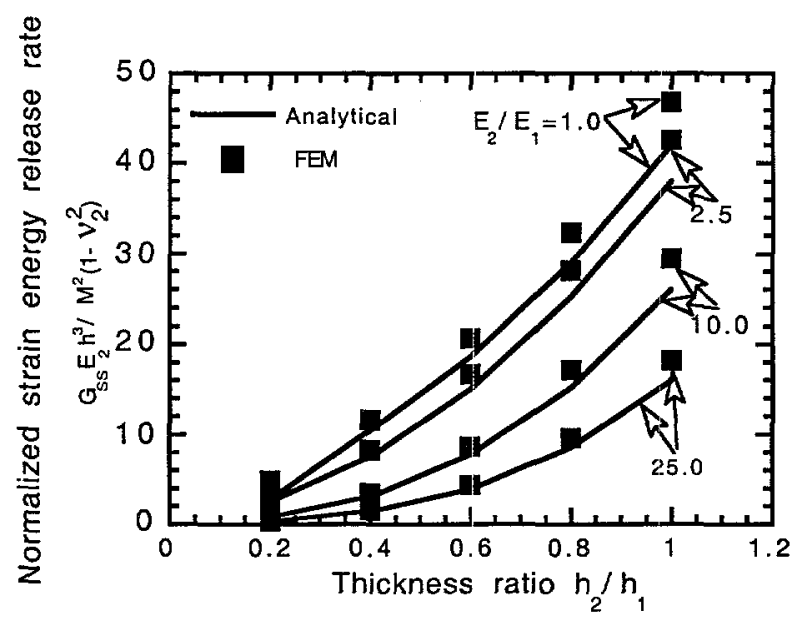

Fig. 18. Comparison of normalized strain energy release rate calculated analytically and by FEM for two Young's modulus ratios.

\subsubsection{FEA Solutions for Metal/Oxide Systems}

A finite-element model was used to calculate strain energy release rates for specimens used in the four-point-bend experiments. Because of the thinness of the oxide scale (1.5 to $5 \mu \mathrm{m})$, some finite elements (away from the crack tip) had relatively high aspect ratios that could introduce small errors into the calculations. Improvement of the mesh would require the use of a substantially greater number of elements, with a consequent increase in computing time. Because crack-tip elements are more important, the same mesh at the crack tip used in the earlier calculations was also used here. Strain energy release rates were calculated for a crack length of $2 \mathrm{a}=6.0 \mathrm{~mm}$ and a virtual crack extension $\Delta \mathrm{a}$ of $0.1 \mathrm{~mm}$.

Variation of the strain energy release rates with bending moment (excluding residual thermal stresses) for the three model alloys are compared in Figs. 20a-b for various oxide thicknesses. Calculated strain energy release rate increases in direct proportion to oxide thickness. The values of $|\mathrm{K}|$ corresponding to the strain energy release rates shown in Figs. $20 \mathrm{a}-\mathrm{b}$ vary from 1 to $10^{-2} \mathrm{MPa}$ $\mathrm{m}^{1 / 2}$. Because the curves were calculated by ignoring the residual stresses, they represent the calculated strain energy release rates at approximately $1000^{\circ} \mathrm{C}$. All of the four-point bend tests on Alloys 1 and 2 at $1000^{\circ} \mathrm{C}$ failed by the unstable cracking of the substrate, which implied that it was energetically favorable for the transverse oxide cracks to grow through the substrate rather than to turn $90^{\circ}$ at the interface and delaminate the oxide scales. Because the calculations assumed a virtual crack growth along the interface, results from these tests are plotted in Fig. 20a by symbols with an arrow indicating that they are lower bounds to the critical strain energy release rate for interfacial cracking. Strain energy release rates for virtual crack extensions into the substrate were not calculated.

In contrast to the high-temperature tests, three of the room-temperature bend tests resulted in oxide cracking and delamination. Critical strain energy release rates were calculated for these tests after including effects of residual thermal stresses. The calculated critical strain energy rates for these tests are shown in Fig. 20a by means of symbols with a scatter band indicating the uncertainty in the calculated energy release rate. Although these were calculated on the basis of a crack with $\mathrm{a}=3 \mathrm{~mm}$, crack length has only a small effect on the calculated strain energy release 
rates for this geometry and loading configuration (see Fig. 19a). The critical strain energy release rate at room temperature is $\approx 0.005 \mathrm{~N} / \mathrm{mm}$ for the oxide scale on Alloys 1 and 2 . Further, the lower bounds to the critical strain energy release rates for Alloys 1 and 2 at $1000^{\circ} \mathrm{C}$ are not much below the critical strain energy release rates at room temperature, indicating that the critical strain energy release rate for delamination may not decrease appreciably with temperature. Inclusion of thermal residual stress has a relatively small influence on the strain energy release rates for thin oxides on Alloys 1 and 2 at room temperature.

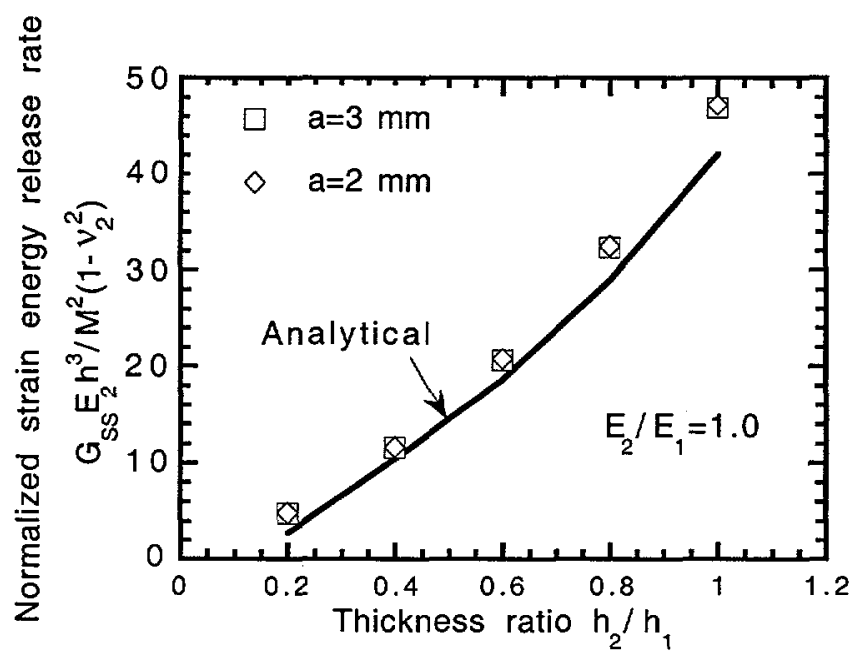

(a)

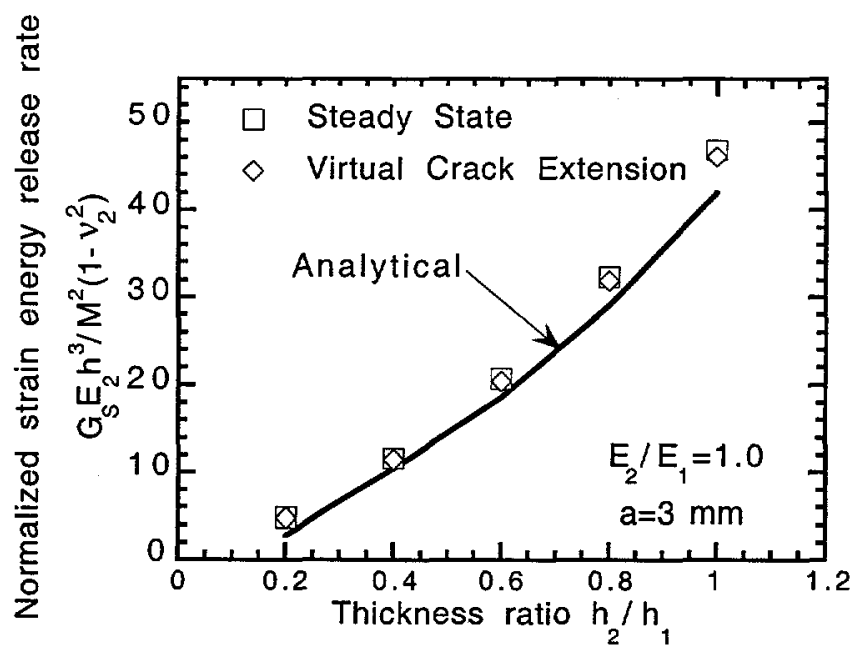

(b)

Fig. 19. Normalized strain energy release rates calculated analytically and by FEA using (a) steadystate values for two crack lengths, and (b) virtual crack extension method with $\Delta a=0.05 \mathrm{~mm}$. 


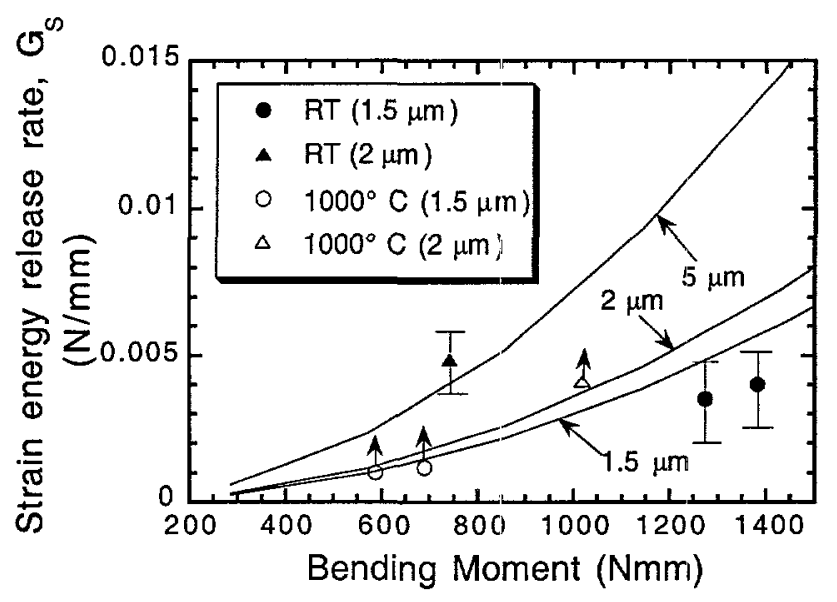

(a)

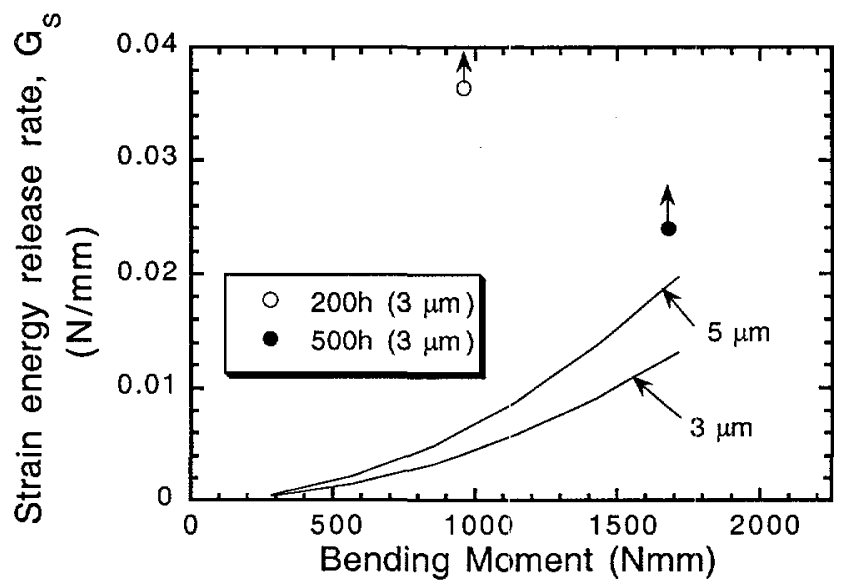

(b)

Fig. 20. Comparison of strain energy release rates of (a) Alloys 1 and 2 at room temperature and $1000^{\circ} \mathrm{C}$ and (b) Alloy 3 at room temperature for different scale thicknesses.

Because none of the oxides on Alloy 3 specimens showed cracking of either the oxide or the substrate in room-temperature bend tests, results from these tests are plotted as symbols with arrow in Fig. 20b to denote that they are lower bounds. Note that although both specimens had 3$\mu \mathrm{m}$-thick oxides, the specimen with the higher bending moment was oxidized for $500 \mathrm{~h}$ at $1000^{\circ} \mathrm{C}$, while that at the lower bending moment was oxidized for $200 \mathrm{~h}$ at the same temperature. Results from the tests at high temperatures are not plotted in Fig. $20 \mathrm{~b}$ because they sustained very low loads (see Table 6) at maximum displacement. In contrast to that in Alloys 1 and 2, inclusion of residual stress effects increases the calculated strain energy release rates significantly because of the greater oxide thickness and larger mismatch in thermal expansion coefficient. The limited data tend to show that Alloy 3 has a higher critical strain energy release rate $(>0.03 \mathrm{~N} / \mathrm{mm})$ at room temperature than do Alloys 1 and 2. 
Because an interfacial stress singularity exists at the edge of the samples even without a crack, 20 scale failure often starts at this point. FEA was used to calculate the strain energy release rate of a 3-mm-long edge crack at the interface upon cooling from elevated temperatures to room temperature. The results are plotted in Fig. 21. Because of a higher mismatch in thermal expansion coefficient, Alloy 3 has higher values of the strain energy release rate than do Alloys 1 and 2. Also, as expected, the strain energy release rates are higher (i.e., an alloy is more prone to brittle fracture) as initial temperature and oxide thickness increase. Thus, depending on interfacial fracture toughness and initial flaw size at the edge, oxide scales may delaminate starting at the edge of the sample. If we use the earlier estimated critical strain energy release rates at room temperature, a 3-mm-long edge crack in a 1-1.5- $\mu \mathrm{m}$-thick oxide on any of Alloys 1,2 or 3 should very likely be stable. On the other hand, a 3-mm-long edge crack in a 5- $\mu \mathrm{m}$-thick oxide on any of the alloys, particularly Alloys 1 and 2, will very likely be unstable on cool-down and lead to delamination, which is in agreement with experience on these alloys. However, the strain energy release rate for an edge crack should be a stronger function of crack length than an internal interfacial crack in the four-point bend configuration. Therefore, the maximum flaw size created at the interface at the edge during fabrication will also be a factor in determining whether edge delamination will occur.

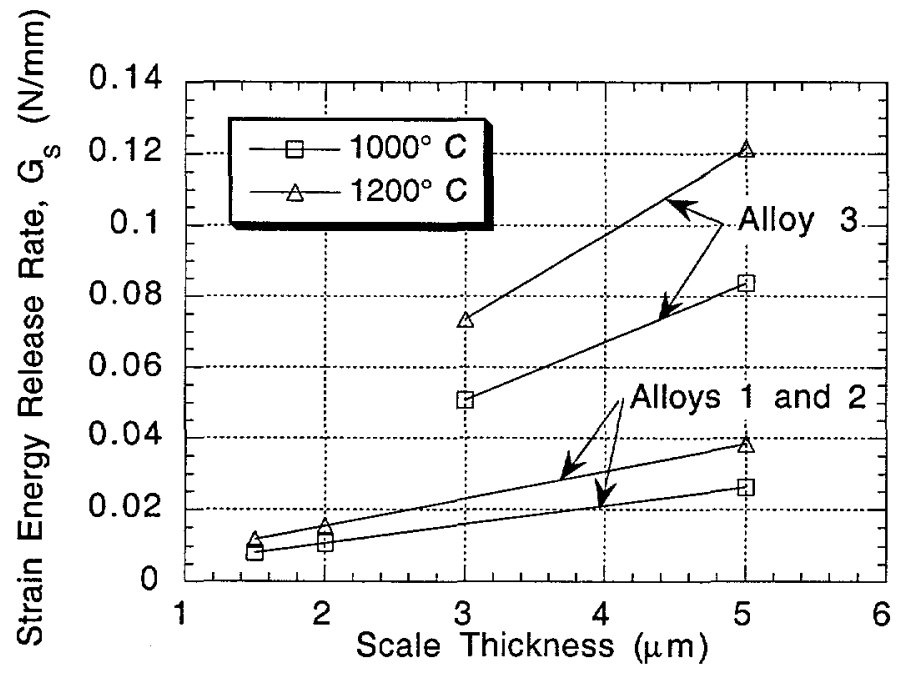

Fig. 21. Strain energy release rate of oxide/alloy interface crack at one end of sample after cooling from high temperatures. 


\section{Discussion of Results and Conclusions}

In the current investigation, we studied the spallation behavior of two Ni-based model alloys of the type Ni10Cr1OAl with or without $0.1 \%$ yttrium addition and one Fe-based model alloy of the type Fe2Cr15Al. Four-point bend tests were conducted to determine the effects of residual stress and applied stress on the failure behavior of the oxide scales. Test specimens were exposed at 1000 and $1200^{\circ} \mathrm{C}$ in air for up to $500 \mathrm{~h}$ to thermally grow oxide scales from 1.5 to $5 \mu \mathrm{m}$ in thickness. The finite-element program ANSYS was used to calculate the residual stresses after cool-down, to calculate the additional stresses during bending, and to calculate the strain energy release rates of cracks at the oxide/alloy interface. Transverse cracks in the oxide scale could cause spallation if it is energetically favorable for the cracks to turn $90^{\circ}$ at the interface rather than penetrate the substrate. Loss of the protective scales in these alloys will raise questions about their use in aggressive environments.

Cyclic oxidation of the Ni-based alloys without yttrium addition (see Figs. 5 and 6) at 1000 and $1200^{\circ} \mathrm{C}$ showed evidence of weight loss in all cases. The alloy with small yttrium addition appears to grow a protective alumina scale. Similar results were found after one cycle of exposure of the test samples (see Fig. 7). For exposures at $1000^{\circ} \mathrm{C}$, the scales are uncracked on cooling to room temperature after $200 \mathrm{~h}$ exposure of both Ni-based alloys and the Fe-based alloys and after $500 \mathrm{~h}$ exposure of the Ni-based alloy with yttrium addition and the Fe-based alloy. Because of higher residual stresses after exposure at $1200^{\circ} \mathrm{C}$, all alloys showed evidence of cracking on cool-down. Addition of yttrium to the Ni-base alloy appears to improve the adherence properties of the oxide scale, which may be expected to have better resistance to oxidizing environment.

For the FEA calculations, two models were used. The first mesh was used to calculate stresses in an oxidized sample without cracks in the oxide scale, and the second mesh was used to simulate an interfacial crack at the oxide/alloy interface. The bending stresses calculated for the oxide scale during bending are 200 to $2000 \mathrm{MPa}$ for the tension and compression sides, depending on the bending moments, but are almost independent of scale thickness. Calculated residual stresses in the oxide scales are compressive and very high. After cooling from exposure temperature, the scales of the $\mathrm{Ni}$-based alloy had residual stresses of $\approx 3000 \mathrm{MPa}$, while the values of the Fe-based alloy were $\approx 6000 \mathrm{MPa}$. These numbers are of the same order as the measured data found in the literature 6 (see Table 2). The higher residual stresses in the Fe alloy are a result of a larger mismatch in the thermal expansion coefficients of the alloy and the alumina scale. Stresses in the substrate bulk material are tensile and low. For the four-point bend tests, the combined residual and bending stresses in the oxide scales on both sides of the specimens are generally compressive.

In the interface crack model, a virtual crack extension method was used to calculate the strain energy release rate. The results agreed well with available analytical calculations (see Eqs. 11-15 and Figs. 18 and 19). For the bend test specimens, an interfacial crack length $2 \mathrm{a}$ of $6.0 \mathrm{~mm}$ and a virtual crack extension of $0.1 \mathrm{~mm}$ were used to calculate the strain energy release rates. Calculated critical strain energy release rates for Alloys 1 and 2 are $\approx 0.005 \mathrm{~N} / \mathrm{mm}$. The corresponding $|\mathrm{K}|$ value as a complex stress intensity factor is $\approx 0.5 \mathrm{MPam}^{1 / 2}$. These are comparable to the reported ${ }^{2}$ $\mathrm{K}_{\mathrm{IC}}$-value of $2.5 \mathrm{MPa} \cdot \mathrm{m}^{1 / 2}$ for $\mathrm{Al}_{2} \mathrm{O}_{3}$. Because the calculated strain energy release rate increases with scale thickness, thicker scales should fail under smaller loads.

The Ni-based alloys failed by oxide cracking and delamination at room temperature during fourpoint bend tests, while the specimens with thicker scales failed at lower stress levels. The calculated bending stresses (excluding residual stress) in the oxide scales at the failure load during the four- 
point bending tests for scale thicknesses of 1.5 and $2.0 \mu \mathrm{m}$ ranged from 500 to $800 \mathrm{MPa}$. At elevated temperature, no scale delamination was observed, possibly because the residual stresses at $1000^{\circ} \mathrm{C}$ were greatly reduced and conditions were energetically favorable for oxide cracks to penetrate the substrate rather than to delaminate the scale. Calculation of the strain energy release rates indicate that the critical strain energy release rate for these alloys may not be reduced appreciably with temperature.

The defect size estimated from the failure data reported in Ref. 2 ranged from $10^{-1}$ to $10^{-3} \mathrm{~mm}$, which are also of the same order as estimated from our measured failure stresses. The lower failure stress of the specimens with thicker scales may be due to larger defect size or greater defect density in the scale. The dependence of the failure stress on oxide thickness is in agreement with FEA calculations (see Fig. 20). The optical and scanning electron microscope observations also point to the same results. Larger spalled areas were found in the compression side than in the tension side, as would be expected from a consideration of residual stresses. Because of the buckling effects observed in Fig. 9, compressive stresses could be an important factor in the failure of the $\mathrm{Al}_{2} \mathrm{O}_{3}$ scales.

None of the Fe-based alloy specimens showed scale cracking or delamination during the fourpoint bend tests. The calculated bending stresses (excluding residual stress) in the oxide scales at the maximum load (to cause a displacement of 2 to $3 \mathrm{~mm}$ ) during the four-point bending tests for a scale thickness of $3.0 \mu \mathrm{m}$ ranged from 500 to $800 \mathrm{MPa}$, indicating that aging effects during time at oxidation temperature may have an influence on the flow properties of this alloy.

\section{Acknowledgment}

The authors thank David Rink for oxidizing the specimens and conducting the four-point bend tests.

\section{References}

1. H. E. Evans, "Modelling oxide spallation," Materials at High Temperatures, Vol. 12, No. 2-3, pp. 219-227, 1994.

2. M. Schuetze, "An approach to a global model of the mechanical behavior of oxide scales," Materials at High Temperatures, Vol. 12, No. 2-3, pp. 237-247, 1994.

3. R. A. Miller, "Thermal barrier coatings for aircraft engines: history and directions," Journal of Thermal Spray Technology, Vol. 6, No. 1, pp. 35-42, 1997.

4. P. Kofstad, High Temperature Corrosion, Elsevier Applied Science, London, New York, 1988.

5. A. M. Huntz, "Stresses in NiO, $\mathrm{Cr}_{2} \mathrm{O}_{3}$ and $\mathrm{Al}_{2} \mathrm{O}_{3}$ oxide scales," Materials Science and Engineering, Vol. A201, pp. 211-228, 1995.

6. C. H. Hsueh and A. G. Evans, "Residual stresses in metal/ceramic bonded strips," Journal of the American Ceramic Society, Vol. 68, No. 5, pp. 241-248, 1985.

7. H. E. Evans and R. C. Lobb, "An investigation of the oxide-spallation process in a $20 \% \mathrm{Cr}$ austenitic steel," in Proceedings of the $9^{\text {th }}$ International Congress on Metallic Corrosion, Toronto, 1984. 
8. P. Hancock and J. R. Nicholls, "Failure of oxide scales," Materials at High Temperatures, Vol. 12, No. 2-3, pp. 209-218, 1994.

9. F. Ernst, "Metal-oxide interfaces," Materials Science and Engineering, Vol. R14, pp. 97-156, 1995.

10. D. Munz and Y. Y. Yang, "Stress singularities at the interface in bonded dissimilar materials under mechanical and thermal loading," Journal of Applied Mechanics, Vol. 59, No. 12, pp. 857$861,1992$.

11. T. L. Becker, J. M. McNaney, R. M. Cannon, and R. O. Ritchie, "Limitations on the use of the mixed-mode delamination beam test specimen: Effects of the size of the region of K-dominance," Mechanics of Materials, Vol. 25, pp. 291-308, 1997.

12. J. R. Rice, "Elastic fracture mechanics concepts for interfacial cracks," Transactions of the ASME, Vol. 55, No. 3, pp. 98-103, 1988.

13. P. G. Charalambides, J. Lund, A.G. Evans, and R. M. McMeeking, "A test specimen for determining the fracture resistance of bimaterial interfaces," Journal of Applied Mechanics, Vol. 56, No. 3, pp. 77-82, 1989.

14. K. Natesan, C. Richier, B. W. Veal, M. Grimsditch, D. Renusch, and A. P. Paulikas, "Chemical and microstructural characterization of thermally grown alumina scales," Argonne National Laboratory Report, ANL/FE-95/02, 1995.

15. M. E. Thurston, and A. T. Zehnder, "Nickel-alumina interfacial fracture toughness: experiments and analysis of residual stress effects," International Journal of Fracture, Vol. 76, pp. 221-241, 1996.

16. J. R. Nichols, D. J. Hall, and P. F. Tortorelli, "Hardness and modulus measurements on oxide scales," Materials at High Temperatures, Vol. 12, No. 2-3, pp. 141-150, 1994.

17. W. H. Cubberly, P. M. Unterweiser, D. Benjamin, C. W. Kirkpatrick, V. Knoll, and K. Nieman, Metals Handbook Ninth Edition - Volume 3 Properties and Selection: Stainless Steels, Tool Materials and Special-Purpose Metals, American Society for Metals, 1980.

18. J. R. Davis, K. M. Mills, S. R. Lampman, et al., Metals Handbook $10^{\text {th }}$ Ed., Volume 1 Properties and Selection: Iron, Steels, and High-Performance Alloys, American Society for Metals, 1990.

19. J. S. Solecki, ANSYS Revision 4.4 Tutorial - Fracture Mechanics, Technical Report of the Swanson Analysis Systems, Inc., 1989.

20. A. R. Akisanya and N. A. Fleck, "Interfacial cracking from the free-edge of a long bi-material strip," International Journal of Solids and Structures, Vol. 34, No. 13, pp. 1645-1665, 1997. 


\section{Distribution for ANL/FE-00/01}

Internal
S. Bhattacharya
R. B. Poeppel
H. Drucker
D. K. Schmalzer
W. A. Ellingson
W. J. Shack
S. Majumdar (5)
D. L. Smith
R. Mattas
TIS Files
K. Natesan (5)

\section{External}

\section{ANL-E Library}

ANL-W Library

\section{Energy Technology Division Review Committee}

H. K. Birnbaum, University of Illinois at Urbana-Champaign

I.-Wei Chen, University of Pennsylvania

E. M. Logothetis, Ford Motor Co., Dearborn, MI

H. S. Rosenbaum, Freemont, CA

S. L. Sass, Cornell University

R. K. Shah, General Motors Corp., Lockport, NY

S. Smialowska, Ohio State University, Columbus

\section{Other - Industry - University}

ABB Lummus Crest, 15 Broad St., Bloomfield, NJ 07003 M. Greene

ABB Combustion Engineering, 911 W. Main St.,

Chattanooga, TN 37402

D. A. Canonico

AEA Industrial Technology, Harwell Laboratory, Materials Development

Division, Bldg. 393, Didcot, Oxfordshire, OX1 1ORA England

H. Bishop

Albany Research Center, 1450 Queen Ave., SW,

Albany, OR 97321-2198

R. Walters

Allison Engine Company, Materials Engineering, PO Box 420, Indianapolis, IN 46206-0420

L. E. Groseclose

Allison Gas Turbine Division, PO Box 420, Indianapolis, IN 46206-0420

P. Khandalwal (Speed Code W-5) 
Three Chimneys, South Moreton Oxon, United Kingdom Michael J. Bennett

EG\&G Idaho, Inc., Idaho National Engineering \& Environmental Laboratory, PO Box 1625, Idaho Falls, ID 83415

R. N. Wright

Electric Power Research Institute, PO Box 10412, 3412 Hillview Avenue, Palo Alto, CA 94303 J. Stringer

Forschuugs Zentrum Jülich GmbH, ICT, Postfach 1913, D-5170 Jülich, Germany H. Barnert-Wiemer

Foster Wheeler Development Corporation, Materials Technology Dept., John Blizard Research Center, 12 Peach Tree Hill Road, Livingston, NJ 07039

J. L. Blough

General Electric Corporate CR\&D, PO Box 8, Bl.dg, K1, MB 265, Schenectady, NY 12301

G. Rowe

INCO Alloys International, Inc., PO Box 1958, Huntington, WV 25720 S. Tassen

Jet Propulsion Laboratory, 4800 Oak Grove Dr., MS-79-21, Pasadena, CA 91020

R. L. Chen

Lawrence Livermore National Laboratory, PO Box 808, Livermore, CA 94551

J. H. Richardson (L-353)

Los Alamos National Laboratory, PO Box 1663, Los Alamos, NM 87545 R. G. Castro - MS G720

NASA Lewis Research Center, 21000 Brookpark Road, Cleveland, $\mathrm{OH} 44135$

N. Jacobson - MS 106-1

National Institute of Standards and Technology, Materials Building, Gaithersburg, MD 20899

S. J. Dapkunas

Oak Ridge National Laboratory, Metals \& Ceramics Section, PO Box 2008, One Bethyl Valley Road, Oak Ridge, TN 37831

R. R. Judkins

I. G. Wright

Office of Naval Research, Code 432, 800 N. Quincy St., Arlington, VA 22217

S. G. Fishman 
RISO National Laboratory, PO Box 49, DK-4000, Roskilde, Denmark Aksel Olsen

Sandia National Laboratories, PO Box 5800, Albuquerque, NM 87185 G. Carlson

Siemens Westinghouse Electric Corporation, 4400 Alafaya Trial, Orlando, FL 32826-2399

B. Seth

Southwest Research Institute, 6620 Culebra Road, PO Drawer 28510, San Antonio, TX 78284

F. F. Lyle, Jr.

The Johns Hopkins University, Materials Science \& Engineering, Maryland Hall, Baltimore, MD 21218

R. E. Green, Jr.

The Materials Properties Council, Inc., United Engineering Center, 345 E. Forty-Seventh St., New York, NY 10017 M. Prager

United Technologies Research Center, Materials Department, 411 Silver Lane, East Hartford, CT 06108

N. S. Bornstein

University of California, Department of Materials Science and Mineral Engineering, University of California, Building 66-Room 247, Berkeley, CA 94720

R. O. Richie

University of Tennessee, Department of Materials Science and Engineering, 434 Dougherty Engineering Building,

Knoxville, TN 37996

R. A. Buchanan

Virginia Polytechnic Institute and State University, Department of Materials Engineering, Blacksburg, VA 24061 K. L. Reifsnyder

West Virginia University, Mechanical \& Aerospace Engineering Department, PO Box 6106, Morgantown, WV 26505

B. Cooper

\section{US Department of Energy}

DOE Idaho Operations Office, 765 DOE Place, Idaho Falls, ID 83406 J. B. Malmo

DOE National Energy Technology Laboratory, PO Box 880, Morgantown, WV 26505

R. A. Bajura

R. C. Bedick

L. K. Carpenter 
L. C. Headley

A. W. Layne

K. E. Markel

H. M. Ness

J. B. Paladino

R. R. Romanosky

D. K. Schmidt

L. Strickland

C. M. Zeh

DOE Oak Ridge Operations Office, Oak Ridge, PO Box 2008, Oak Ridge, TN 37831-6269

M. A. Rawlins

DOE Office of Basic Energy Sciences, Materials Sciences Division, ER-13, 19901 Germantown Road, Germantown, MD 20874-1290 T. Fitzimmons

I: Thomas

DOE Office of Energy Efficiency and Renewable Energy, Forrestal Building, Washington, DC 20545 W. Parks

DOE Office of Fossil Energy, Forrestal Building, Washington, DC 20585

V. Der

H. Feibus

C. Kinney

J. Yu Shang

M. I. Singer

DOE Office of Industrial Technologies, 1000 Independence Avenue, SW, Washington, DC 20585

C. Sorrell

P. Hoffman

DOE National Energy Technology Laboratory,

PO Box 10940, Pittsburgh, PA 15236

U. Rao

L. Ruth

J. P. Strakey

B. R. Utz

DOE Office of Scientific and Technical Information,

PO Box 62, Oak Ridge, TN 37831 